\title{
Plant Metabolites Drive Different Responses in Caterpillars of Two Closely Related Helicoverpa Species
}

\author{
Longlong Sun ${ }^{1+}$, Wenhua Hou' ${ }^{1+}$, Jiajia Zhang ${ }^{1}$, Yuli Dang', Qiuyun Yang ${ }^{2}$, \\ Xincheng Zhao ${ }^{1}$, Ying $\mathrm{Ma}^{2 *}$ and Qingbo Tang ${ }^{1 *}$ \\ ${ }^{1}$ The Institute of Chemical Ecology and College of Plant Protection, Henan Agricultural University, Zhengzhou, China, \\ ${ }^{2}$ College of Agronomy, Henan Agricultural University, Zhengzhou, China
}

OPEN ACCESS

Edited by:

Peng $\mathrm{He}$,

Guizhou University, China

Reviewed by:

Ya-Nan Zhang,

Huaibei Normal University, China

Roberto Massimo Crnjar,

University of Cagliari, Italy

*Correspondence:

Ying $\mathrm{Ma}$

maying999@126.com

Qingbo Tang

qingbotang@126.com;

qbtang@henau.edu.cn

${ }^{\dagger}$ These authors have contributed

equally to this work

Specialty section:

This article was submitted to Invertebrate Physiology, a section of the journal

Frontiers in Physiology

Received: 02 February 2021

Accepted: 16 March 2021

Published: 21 April 2021

Citation:

Sun L, Hou W, Zhang J, Dang Y, Yang $Q$, Zhao $X$, Ma Y and Tang $Q$

(2021) Plant Metabolites Drive Different Responses in Caterpillars of Two Closely Related Helicoverpa Species. Front. Physiol. 12:662978. doi: 10.3389/fphys.2021.662978
The host acceptances of insects can be determined largely by detecting plant metabolites using insect taste. In the present study, we investigated the gustatory sensitivity and feeding behaviors of two closely related caterpillars, the generalist Helicoverpa armigera (Hübner) and the specialist H. assulta (Guenée), to different plant metabolites by using the single sensillum recording technique and the dual-choice assay, aiming to explore the contribution of plant metabolites to the difference of diet breadth between the two species. The results depicted that the feeding patterns of caterpillars for both plant primary and secondary metabolites were significantly different between the two Helicoverpa species. Fructose, glucose, and proline stimulated feedings of the specialist $H$. assulta, while glucose and proline had no significant effect on the generalist $H$. armigera. Gossypol and tomatine, the secondary metabolites of host plants of the generalist $H$. armigera, elicited appetitive feedings of this insect species but drove aversive feedings of $H$. assulta. Nicotine and capsaicin elicited appetitive feedings of $H$. assulta, but drove aversive feedings of $H$. armigera. For the response of gustatory receptor neurons (GRNs) in the maxillary styloconic sensilla of caterpillars, each of the investigated primary metabolites induced similar responding patterns between the two Helicoverpa species. However, four secondary metabolites elicited different responding patterns of GRNs in the two species, which is consistent with the difference of feeding preferences to these compounds. In summary, our results of caterpillars' performance to the plant metabolites could reflect the difference of diet breadth between the two Helicoverpa species. To our knowledge, this is the first report showing that plant secondary metabolites could drive appetitive feedings in a generalist insect species, which gives new insights of underscoring the adaptation mechanism of herbivores to host plants.

Keywords: Helicoverpa armigera, Helicoverpa assulta, plant primary metabolites, plant secondary metabolites, feeding preference, electrophysiological response, gustatory receptor neurons

\section{INTRODUCTION}

The herbivorous insects use a variety of physiological mechanisms including pre-ingestive responses (i.e., chemosensory) (Bernays et al., 2000a; Glendinning, 2002), the post-ingestive response (Montandon et al., 1987; Behmer et al., 1999; Wright et al., 2010; Simões et al., 2012), and the detoxification processes (Mao et al., 2007; Tao et al., 2012; Bretschneider et al., 2016; 
Krempl et al., 2016; Tian et al., 2019) to cope with the plant metabolites, including primary and secondary metabolites. It is also accepted that herbivorous insects with different diet breadths have different capacities to discriminate these metabolites and extend to their decisions in host acceptance (Bernays et al., 2000b; Govind et al., 2010; Ahn et al., 2011; Liu et al., 2012; Kumar et al., 2014; Wang et al., 2017; Zhu et al., 2020). For example, the specialist herbivores were frequently reported to have more ability to metabolize or utilize the secondary metabolites than the generalists (Bernays et al., 2000b; Govind et al., 2010; Ahn et al., 2011; Liu et al., 2012; Kumar et al., 2014; Sun et al., 2019). Some specialists even detect the secondary metabolites as "token stimuli" for recognizing the specific host plant by using their chemoreceptors (Jermy, 1966; Schoonhoven, 1967; Renwick and Lopez, 1999; del Campo et al., 2001; Vickerman and de Boer, 2002; Miles et al., 2005). However, little attention has been paid in understanding whether the generalist herbivorous insects could recognize the plant metabolites from their hosts as "token' timuli."

The dietary acceptance and host range of caterpillars might relate to the spectrum of the sensitivity of gustatory receptor neurons (GRNs) in the galeal styloconic sensilla to the plant metabolites (Jermy, 1966; Thompson, 1991; Bernays et al., 2000b; Wada-Katsumata et al., 2013; Sollai and Crnjar, 2019). Therefore, comparing feeding behaviors and taste responses between closely related species with different host ranges could contribute to understanding the host acceptability, diet breadth, and evolution of host adaptation (Sheck and Gould, 1996; Bernays et al., 2000b; Renwick, 2001; Liu et al., 2012; Sollai et al., 2014). The cotton bollworm Helicoverpa armigera (Hübner) (Lepidoptera: Noctuidae) and the tobacco budworm Helicoverpa assulta (Guenée) (Lepidoptera: Noctuidae) are two sympatric closely related herbivorous species. The former is an extreme generalist feeding on at least 161 host plant species in 49 plant families, including cotton, tomato, and tobacco (Zalucki et al., 1986; Fitt, 1989), whereas the latter is a specialist insect species feeding on the Solanaceae and several Physalis species, tobacco, and hot pepper on the natural field (Mitter et al., 1993). The two species could be hybridized to produce viable offspring under laboratory conditions (Wang and Dong, 2001) and are good models to investigate the interaction between plants and herbivorous insects (Tang et al., 2006, 2014; Ahn et al., 2011; Liu et al., 2012; Yang et al., 2017; Zhu et al., 2020).

In this study, we investigated the feeding preferences and the gustatory responses of caterpillars of the two Helicoverpa species to three plant primary metabolites, including fructose, glucose, and proline, and four plant secondary metabolites including gossypol, tomatine, nicotine, and capsaicin (Table 1). Fructose, glucose, and proline have been well known to be the energy source and phagostimulants for herbivorous insects (Albert et al., 1982; Bernays and Chapman, 2001; Liscia et al., 2004; Jiang et al., 2015; Mang et al., 2016). Gossypol and tomatine are plant secondary metabolites of cotton (Oliver et al., 1970; Montandon et al., 1987) and tomato, respectively (Barbour and Kennedy, 1991). Nicotine and capsaicin are plant secondary metabolites of tobacco and pepper, respectively (Pearson et al., 2019). Finally, we attempt to understand whether behavioral responses of two
TABLE 1 | The investigated plant metabolites and the corresponding host plants of the two Helicoverpa species.

\begin{tabular}{lcc}
\hline Species & Host plant & Secondary metabolites \\
\hline H. armigera & Cotton & Gossypol \\
& Tomato & Tomatine \\
& Tobacco & Nicotine \\
H. assulta & Hot pepper & Capsaicin \\
& Tobacco & Nicotine \\
& Hot pepper & Capsaicin \\
\hline
\end{tabular}

Helicoverpa species toward these plant metabolites corresponded with the diet breadth or not.

\section{MATERIALS AND METHODS}

\section{Insect Culture}

All colonies of the Helicoverpa caterpillars were maintained in the laboratory at $75 \% \pm 5 \%$ relative humidity and temperature $\left(27 \pm 1^{\circ} \mathrm{C}\right)$ under a controlled photoperiod (L16:D8). Both larvae of $H$. armigera and $H$. assulta were obtained from established laboratory colonies, which were reared on an artificial diet prepared from the following ingredients: wheat bran (150 g), soybean powder (80 g), yeast powder (25 g), casein (40 g), sorbic acid (3 g), ascorbic acid (3 g), sucrose (10 g), agar (20 g), vitamin composite powders ( $8 \mathrm{~g})$, acetic acid $(4 \mathrm{ml})$, and distilled water (1,500 ml) (Wu et al., 1990; Wu and Gong, 1997; Jiang et al., 2010). Adults were supplied with a $10 \% \mathrm{v} / \mathrm{v}$ solution of sucrose in water.

\section{Compounds}

D-(-)-Fructose (Cas:57-48-7), D-(+)-glucose (Cas:50-99-7), L-proline (Cas:147-85-3), gossypol (Cas:303-45-7), capsaicin (Cas:2444-86-4), and tomatine (Cas:17406-45-0) were obtained from Beijing Solarbio Science \& Technology Co., Ltd. Nicotine (Cas:54-11-5) was from Alfa Aesar. Ethanol absolute (Cas:6417-5) and methanol (Cas:67-56-1) were from Tianjin De-En Chemical Reagent Co., Ltd. PVP (Cas:9003-39-8) was obtained from Tianjin Guangfu Fine Chemical Research Institute.

\section{Feeding Choice Assay}

The dual-choice plant leaf disc bioassay was used to test the feeding preference of 5 th instar larvae of the two Helicoverpa species as described by Wang et al. (2017). In general, leaf discs (10 $\mathrm{mm}$ diameter, about $156 \mathrm{~mm}^{2}$ ) were punched from fresh leaves of pepper Capsicum frutescens L., "Yu-Yi" (Solanaceae), which then were immersed in control or treatment solutions for $30 \mathrm{~min}$. The plant primary metabolites $\mathrm{D}$-fructose $(1.0,10$, 30, $50 \mathrm{mM})$, D-glucose $(1.0,10,30,50 \mathrm{mM})$, and L-proline $(0.1,1.0,10,50 \mathrm{mM})$ were dissolved in water. The plant secondary metabolites gossypol, tomatine, and capsaicin were dissolved in solvent I (0.25\% methanol, 5\% ethanol, and $0.32 \%$ polyvinylpyrrolidone (PVP) in water) at $0.001,0.01,0.1$, and $1.0 \mathrm{mM}$. Nicotine was dissolved in solvent II $(0.16 \%$ PVP in 
water) at the concentrations of $0.001 \mathrm{mM}, 0.01 \mathrm{mM}, 0.1 \mathrm{mM}$, and $1.0 \mathrm{mM}$. The solvents were used as control.

Before the test, the fifth-instar caterpillars had been starved for about $8 \mathrm{~h}$. A single caterpillar was placed in the center of a Petri dish (12 cm diameter) with a moist filter paper $(\Phi 11 \mathrm{~cm}$, Jiaojie $^{\circledR}$, China). Four solvent-treated leaf discs and four plant metabolite-treated leaf discs were arranged in an ABABABAB fashion around the dish. All Petri dishes were put under evenly distributed LED strip lights $(8,000 \mathrm{Lm})$ at a temperature of $27 \pm 1^{\circ} \mathrm{C}$. Areas of all remnants of leaf discs were measured by using a transparency film (PP2910, 3M Corp.) when two of the four disks of either plant (A or B) had been consumed. Each caterpillar was tested only once. For the feeding preference assays, at least 90 replicates were conducted.
The feeding preference index was calculated as follows:

Preference index for control leaves $(\mathrm{Pc})=$ area of controldisc consumed/(area of control-disc consumed + area of treatment-disc consumed)

Preference index for treatment leaves $(\mathrm{Pt})=$ area of treatment-disc consumed/(area of control-disc consumed + area of treatment-disc consumed)

\section{Electrophysiological Recordings}

The electrophysiological sensitivity of gustatory neurons in the styloconic sensilla on the maxillary galea of caterpillars to the plant metabolites was investigated using the single sensillum recording technique (van Loon, 1990; Roessingh et al., 1999). In

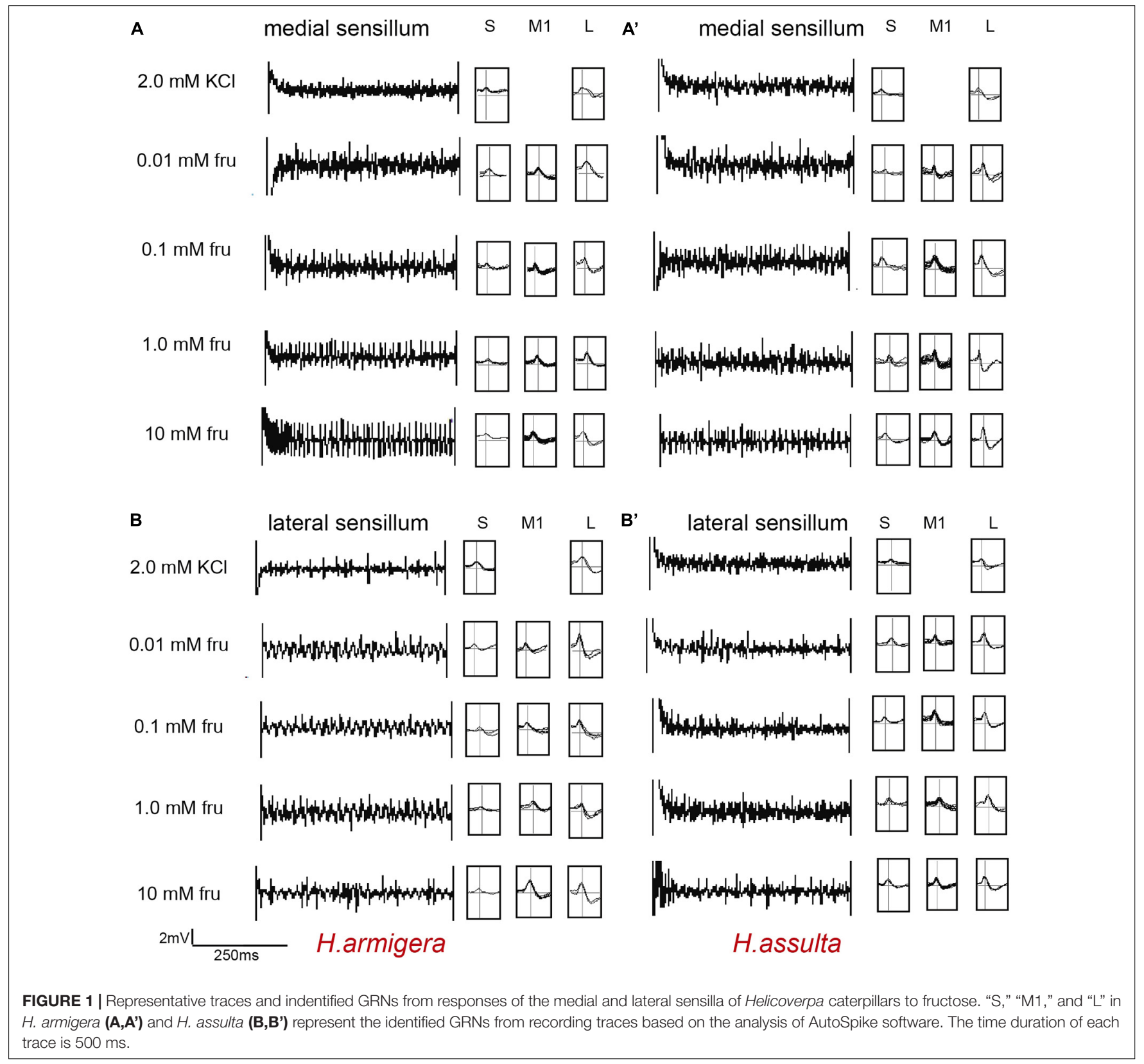


brief, a head of an excised 5th instar caterpillar was mounted on a silver wire electrode which was connected to the input of a pre-amplifier (Syntech Taste Probe DTP-1, Hilversum, The Netherlands). The lateral or medial styloconic sensillum was recorded for the sensitivity to a stimulus at different concentrations. D-fructose, D-glucose, and L-proline were used as stimuli of primary metabolites with concentrations varying from $0.01,0.1,1.0$ to $10 \mathrm{mM}$ in $2 \mathrm{mM} \mathrm{KCl}$. The previous work has shown that $2 \mathrm{mM} \mathrm{KCl}$ was an adequate electrolyte solvent for Helicoverpa caterpillars (Tang et al., 2015; Ma et al., 2016). The concentrations of gossypol, capsaicin, tomatine, and nicotine were from $0.001,0.01,0.1$ to $1.0 \mathrm{mM}$. The first three stimuli were dissolved in solvent I, and nicotine was in solvent II. Both solvents for electrophysiological tests consist of $2 \mathrm{mM} \mathrm{KCl}$. In case of synergistic interactions of mixed metabolites to GRNs, only a single sensillum in one caterpillar was tested for the responses to one kind of stimulus from low to high concentration. The electrolyte solvent was also tested as the control. For a single test, a glass microelectrode (tip diameter $c a .30 \mu \mathrm{m}$ ) filled with a stimulating solution was moved to contact with the tip of the lateral or medial sensillum with the aid of a micromanipulator. The duration of a single stimulation was $2 \mathrm{~s}$ with a time interval of at least $3 \mathrm{~min}$. Amplified signals were digitized by an A/D interface (IDAC-4, Syntech) and sampled into a personal
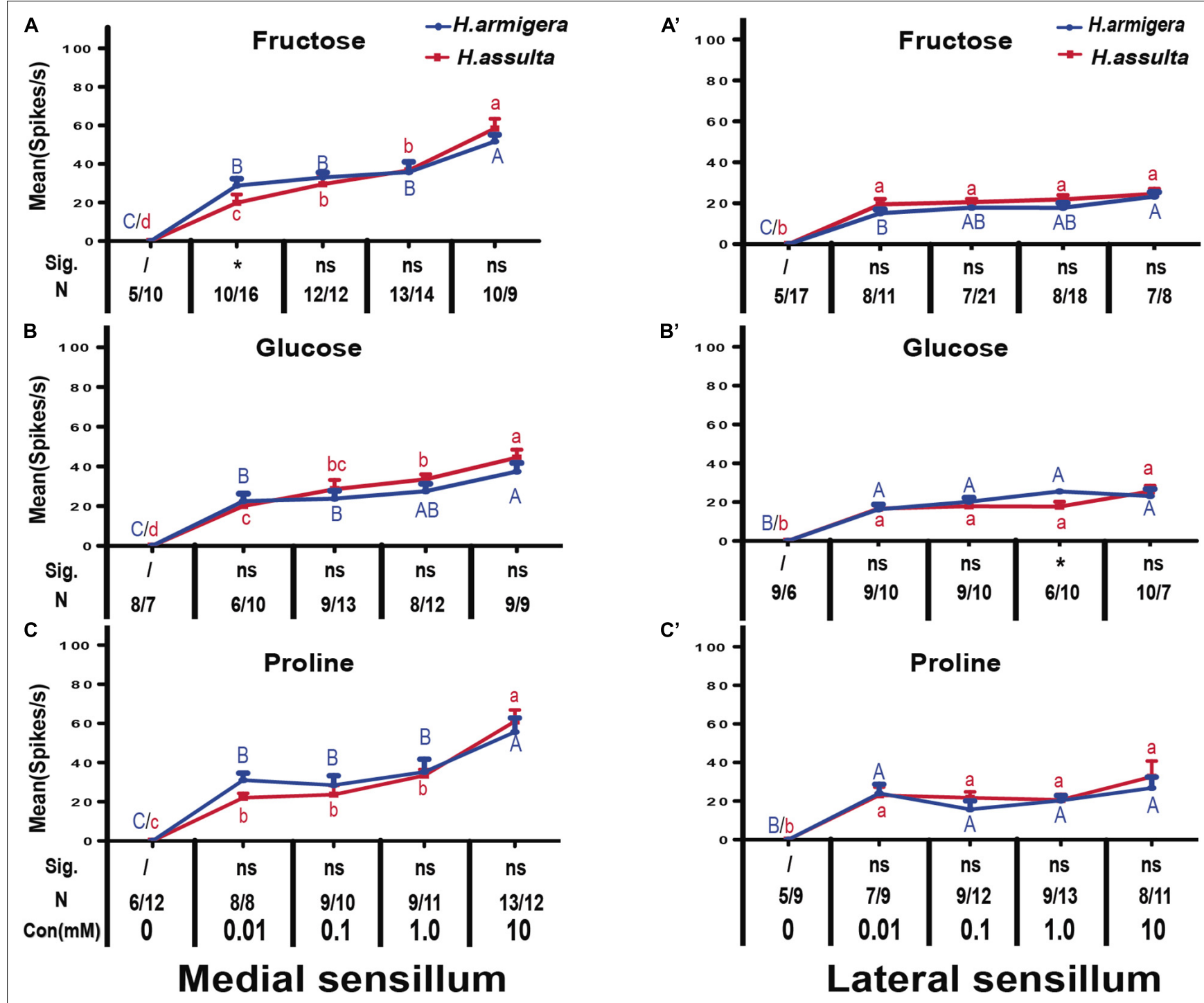

FIGURE 2 | Comparisons of gustatory responses of "M1" GNRs in styloconic sensilla of Helicoverpa caterpillars to plant primary metabolites. Curves show the mean responding frequency \pm SE of "M1" GNRs in the medial sensillum (A-C) and in the lateral sensillum (A'-C') of Helicoverpa caterpillars to plant primary metabolites from 0.01 to $10 \mathrm{mM}$. Different capital letters and lowercase letters represent the mean responding frequencies of "M1" GNRs were significantly different in response to one primary metabolite at different concentrations in caterpillars of $H$. armigera and $H$. assulta, respectively (post-hoc SNK test of ANOVA: $P<0.05$ ). Independent $t$-test was used to compare the difference of the mean responding frequency of "M1" GNRs to the same compound at the same concentration between the two Helicoverpa species. "Sig." represents the levels of difference. "ns": no significant different $(P>0.05)$; "*” represents the difference was significant at the 0.05 level. "N" represents the number of tested caterpillars of $H$. armigera/H. assulta. 


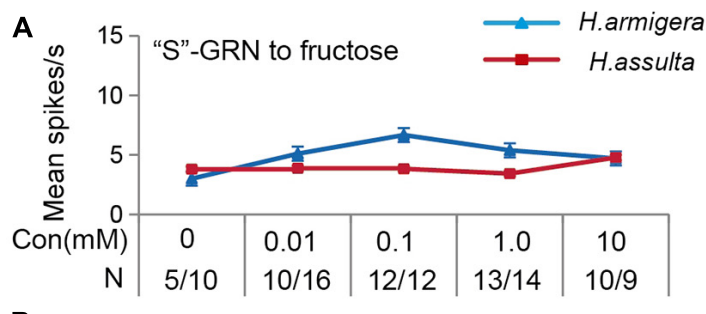

B

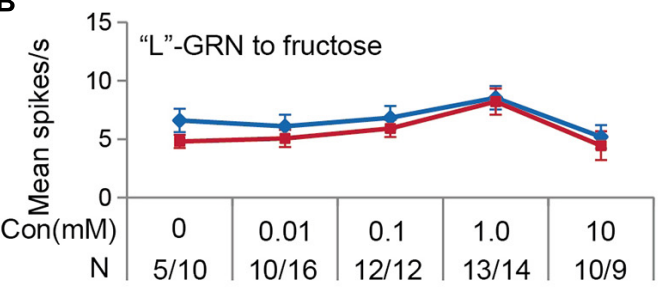

C

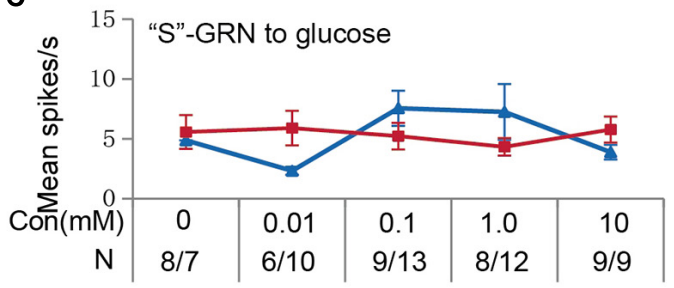

D

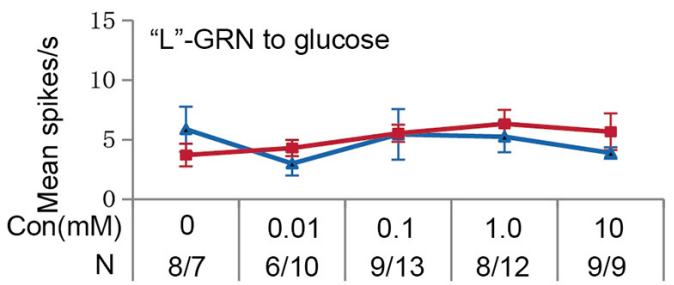

E

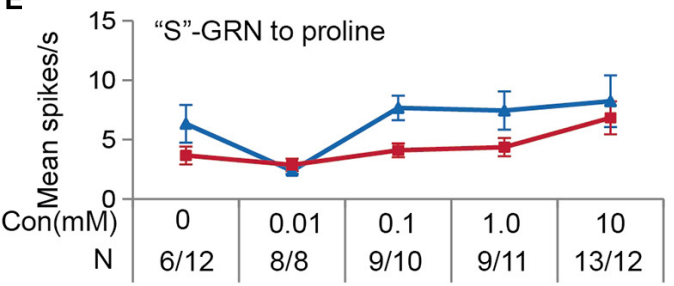

$\mathbf{F}$

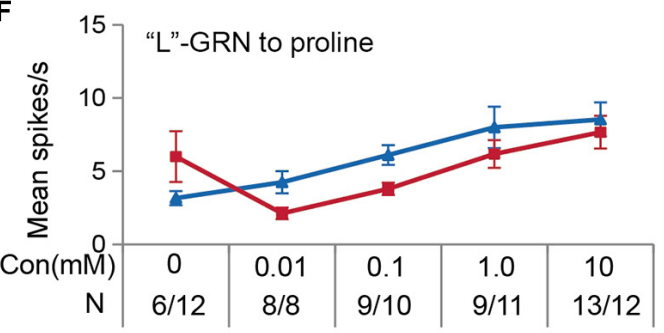

A' 15 "S" GRN to fructose $\longrightarrow$ H.armigera

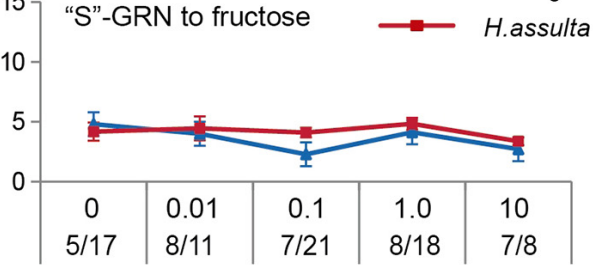

B

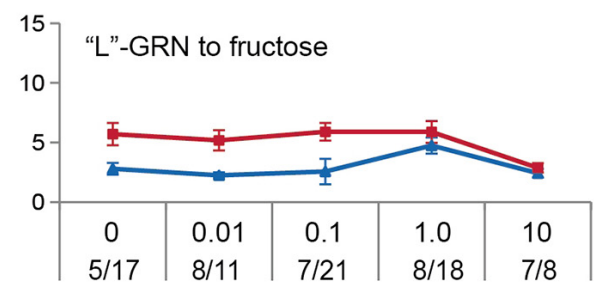

C'

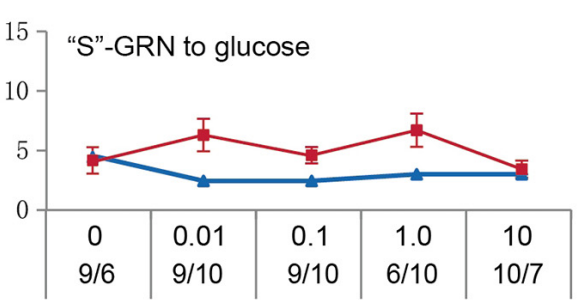

D'

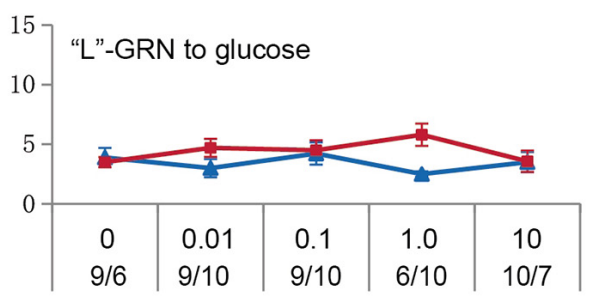

E'

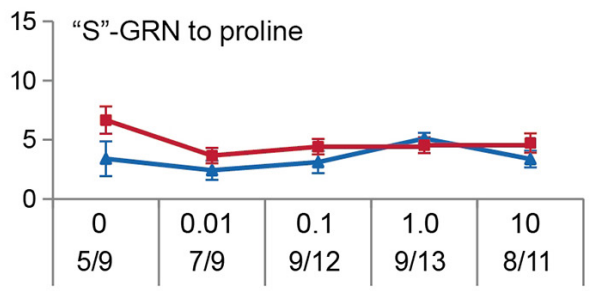

$F^{\prime}$

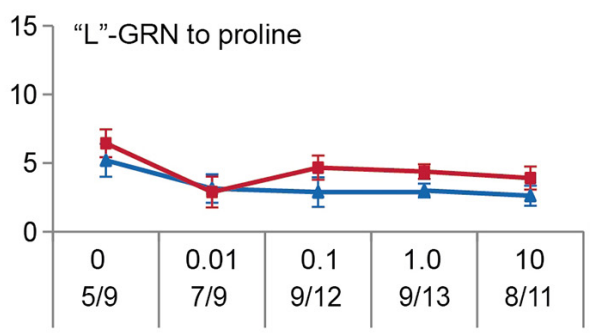

Lateral sensillum

FIGURE 3 | Responses of "S" and "L" GRNs in the styloconic sensilla of Helicoverpa caterpillars to the three primary metabolites. (A,C,E): responses of the indentified "S" GRNs from the medial sensillum to fructose, glucose, and proline, respectively; (B,D,F): responses of the indentified "L" GRNs from the medial sensillum to fructose, glucose, and proline, respectively; (A',C',E'): responses of the indentified "S" GRNs from the lateral sensillum to fructose, glucose, and proline, respectively; (B',D',F'): responses of the indentified "L" GRNs in the lateral sensillum to fructose, glucose, and proline, respectively. 
computer. For each given concentration of a stimulus, the electrophysiological responses of at least 10 larvae were recorded.

The analysis of electrophysiological responses of styloconic sensilla to different stimuli was performed with the aid of AutoSpike v. 3.7 software (Syntech, Hilversum, The Netherlands). Briefly, in the case of the identification of GRNs, by measuring the amplitude, shape, and phasic temporal pattern, three impulse spikes were generally identified and labeled as small (S), intermediate (M), and large (L), which best responded to water, metabolites, and salt, respectively (Sollai et al., 2014; Ma et al., 2016). For distinguishing M-type spikes induced by primary metabolites and secondary metabolites, the intermediate
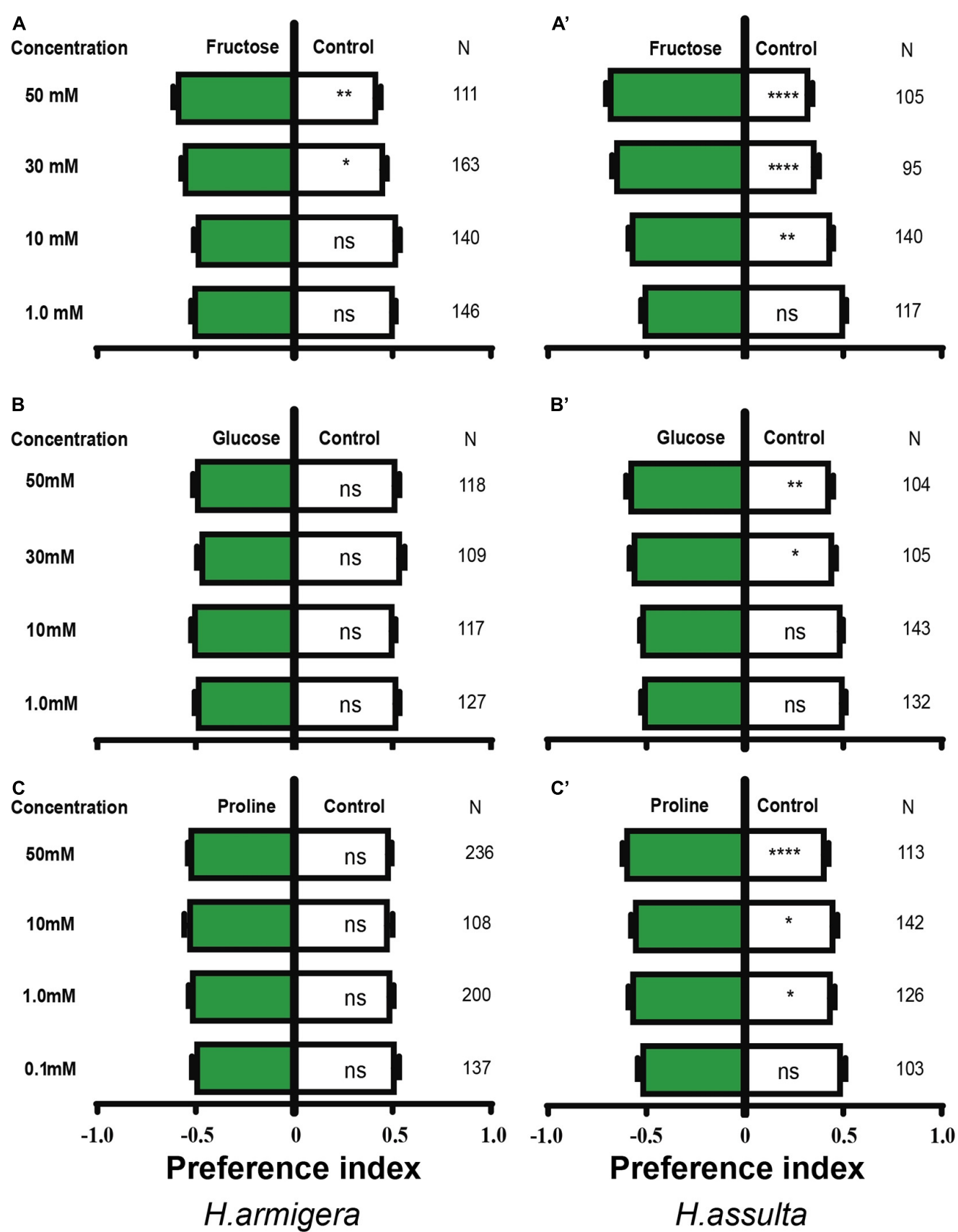

FIGURE 4 | Effects of three primary metabolites on the feeding preferences of Helicoverpa caterpillars. The preference indexes of caterpillars for primary metabolites (green bars) and for control leaves (white bar) were compared. The dual-choice assay was used to test the feeding preference for control and pepper leaves treated by primary metabolites and water, respectively. (A-C): H. armigera caterpillars; (A'-C'): H. assulta caterpillars. A paired-sample $t$-test was used to compare the

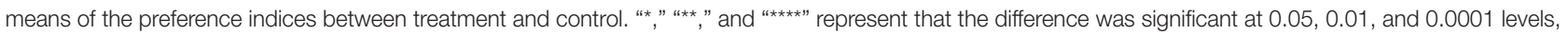
respectively. NS: non-significant difference. N: the number of tested caterpillars. 
1 (M1) and intermediate 2 (M2) were assigned based on the spike amplitudes, correspondingly. The mean impulse frequency of each GRN in the first second (spk.s ${ }^{-1}$ ) was calculated.

\section{Statistical Analysis}

For the comparison of feeding preferences of caterpillars between control and treatment, the value of the preference index was arcsine transformed and then subjected to the paired-sample $t$-test $(P<0.05)$.

All the values of the impulse frequency $\left(\mathrm{spk} . \mathrm{s}^{-1}\right)$ were squareroot transformed before analysis. One-way ANOVA followed by the Student-Newman-Keuls (SNK) post-hoc test $(P<0.05)$ was used to compare the difference of the firing frequency of one type of GNR to one stimulus at different concentrations. The independent $t$-test was used to compare the mean impulse frequency of the same type of GRN between species. Finally, the GLM-Univariate was used to analyze the order of the mean impulse frequency of one type of GRNs to different compounds within species followed by the SNK post-hoc test for multiple comparisons $(P<0.05)$. All data were analyzed using SPSS software version 16.0 .

\section{RESULTS}

\section{Electrophysiological Responses to Primary Metabolites}

In most recordings, three types of GRNs were identified from both medial and lateral sensilla of two Helicoverpa species in response to three plant primary metabolites, labeled as the " $\mathrm{S}$ " GRNs, "M1" GRNs, and "L" GRNs which best responded to water, primary metabolites, and salt, respectively (e.g., see identified representative GRNs in Figure 1). In the medial sensillum, the responses of "M1" GRNs of $H$. armigera caterpillars to each

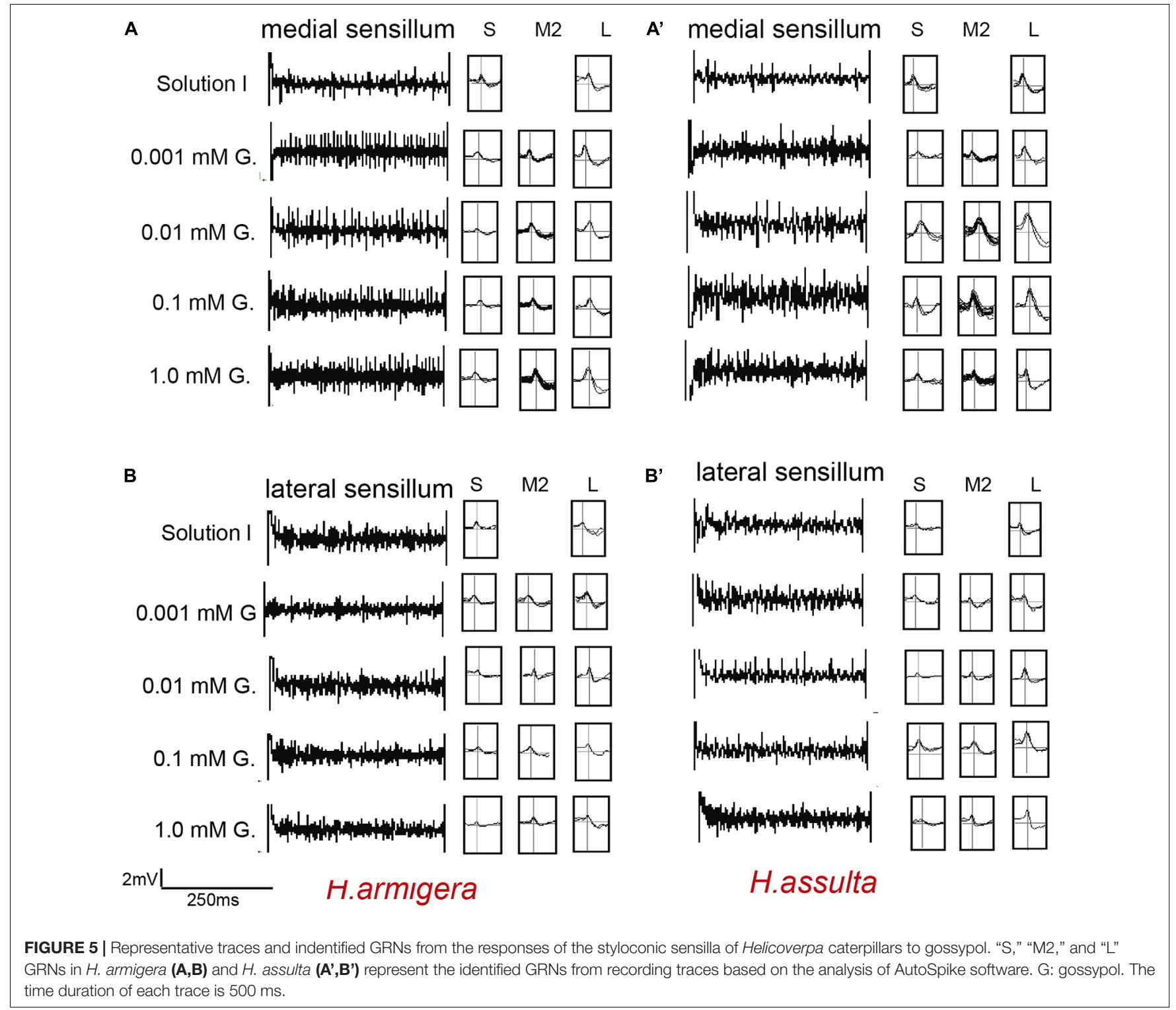


primary metabolite increased with the concentration increasing from $0,0.01 \mathrm{mM}, 0.1 \mathrm{mM}, 1.0 \mathrm{mM}$ to $10 \mathrm{mM}$ [Figure $2 \mathrm{~A}$, oneway ANOVA of fructose: $F_{(4,45)}=37.393, P<0.0001$; Figure 2B, glucose: $F_{(4,35)}=51.272, P<0.0001$; Figure $2 \mathrm{C}$, proline: $\left.F_{(4,40)}=29.965, P<0.0001\right]$. The mean response frequencies of "M1" GRNs of $H$. armigera induced by $10 \mathrm{mM}$ fructose, $10 \mathrm{mM}$ glucose, and $10 \mathrm{mM}$ proline were $51.70 \pm 3.490 \mathrm{spk} \cdot \mathrm{s}^{-1}$, $37.44 \pm 4.378 \mathrm{spk} . \mathrm{s}^{-1}$, and $55.62 \pm 7.161 \mathrm{spk} . \mathrm{s}^{-1}$, respectively.

Similarly, "M1" GRNs in the medial sensillum of $H$. assulta also showed increasing responses to each primary metabolite with increasing concentrations $[H$. assulta in Figure 2A'; oneway ANOVA of fructose: $F_{(4,56)}=99567, P<0.0001$; Figure 2B', glucose: $F_{(4,46)}=55.164, P<0.0001$; Figure 2C', proline: $\left.F_{(4,48)}=93.889, P<0.0001\right]$. The mean response frequency of "M1" GRNs in the medial sensillum of $H$. assulta to $10 \mathrm{mM}$ fructose, $10 \mathrm{mM}$ glucose, and $10 \mathrm{mM}$ proline were

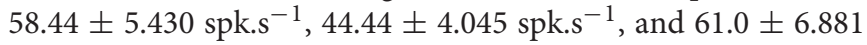
spk.s ${ }^{-1}$, respectively. The responses of "M1" GRNs in the medial sensillum to one stimulus with the same concentration were always not significantly different between the two Helicoverpa species (Figures $2 \mathrm{~A}-\mathbf{C}$, all comparisons: $P>0.05$ ) except fructose at $0.01 \mathrm{mM}$ which induced a significantly higher response of "M1" GRNs in H. armigera than that in $H$. assulta (Figure 2A, independent-sample $t$-test: $\mathrm{df}=24, t=2.411, P=0.024)$. In the lateral sensillum, in contrast, the responses of "M1" GRNs to the three primary metabolites were low and the responses were similar between caterpillars of the two species (Figures 2A'-C').

We also compared the general responding patterns of " $\mathrm{M} 1$ " GRNs in one sensillum within the same species to the three primary metabolites using the GLM-Univariate with compounds and concentration as the fixed factors. It shows that the responses of "M1" GRNs in the medial sensillum of $H$. armigera caterpillars to the three compounds were significantly affected by both compounds and concentration (GLM-Univariate: compounds, $\mathrm{df}=2, F=4.199, P=0.017$; concentration, $\mathrm{df}=4, F=107.877$, $P<0.0001)$. Analysis of the SNK post-hoc test showed that the responses of "M1" GRNs in the medial sensillum of $H$. armigera to glucose were significantly lower than those to fructose and proline (SNK post-hoc test: $P<0.05$ ). However, for $H$. assulta caterpillars, the responses of "M1" GRNs in medial sensillum of $H$. assulta to the three compounds were not significantly affected by compound (GLM-Univariate: compounds, $\mathrm{df}=2, F=1.040$, $P=0.356$; concentration, $\mathrm{df}=4, F=234.979, P<0.0001)$. Similarly, the responses of "M1" GRNs in lateral sensillum in both Helicoverpa species to the three compounds were also not significantly affected by compounds but affected significantly by concentrations (GLM-Univariate of $H$. armigera: compounds, $\mathrm{df}=2, F=0.563, P=0.571$; concentration, $\mathrm{df}=4, F=88.709$, $P<0.0001$; GLM-Univariate of $H$. assulta: compounds, $\mathrm{df}=2$, $F=1.630, P=0.199 ;$ concentration, $\mathrm{df}=4, F=22.90$, $P<0.0001)$.

The three primary metabolites also induced responses of " $\mathrm{S}$ " GRNs and "L" GRNs in both sensilla of the two Helicoverpa species. While the responses of the two types of GRNs to each compound were low with a non-significant change among different concentrations (SNK test after ANOVA for each compound: $P>0.05$ ) (Figure 3).

\section{Feeding Preferences for Primary Metabolites}

The high concentration of fructose drove obvious appetitive feedings of both $H$. armigera caterpillars [Figure 4A; pairedsample $t$-test: $30 \mathrm{mM}, t(162)=-1.999, P=0.047 ; 50 \mathrm{mM}$, $t(110)=-2.88, P=0.005$ ] and $H$. assulta caterpillars [Figure $4 \mathbf{A}^{\prime}$; paired-sample $t$-test: $10 \mathrm{mM}, t(139)=-3.329, P=0.002$; $30 \mathrm{mM}, t(94)=-5.704, P<0.0001 ; 50 \mathrm{mM}, t(104)=-7.116$, $P<0.0001]$. However, glucose showed no obvious effect on the feeding of $H$. armigera at the given concentrations [Figure 4B; paired-sample $t$-test: $1 \mathrm{mM}, t(126)=0.700, P=0.485 ; 10 \mathrm{mM}$, $t(116)=-0.218, P=0.828 ; 30 \mathrm{mM}, t(108)=1.358, P=0.177$; $50 \mathrm{mM}, t(117)=0.522, P=0.602]$, while it drove appetitive feedings of $H$. assulta caterpillars at high concentrations [Figure 4B'; paired-sample $t$-test: $30 \mathrm{mM}, t(104)=-2.308$, $P=0.023 ; 50 \mathrm{mM}, t(103)=-2.865, P=0.004]$.

Similarly, proline had no significant effect on the feeding of $H$. armigera caterpillars [Figure 4C; paired-sample $t$-test: $0.1 \mathrm{mM}, t(136)=0.400, P=0.690 ; 1.0 \mathrm{mM}, t(199)=-0.803$,

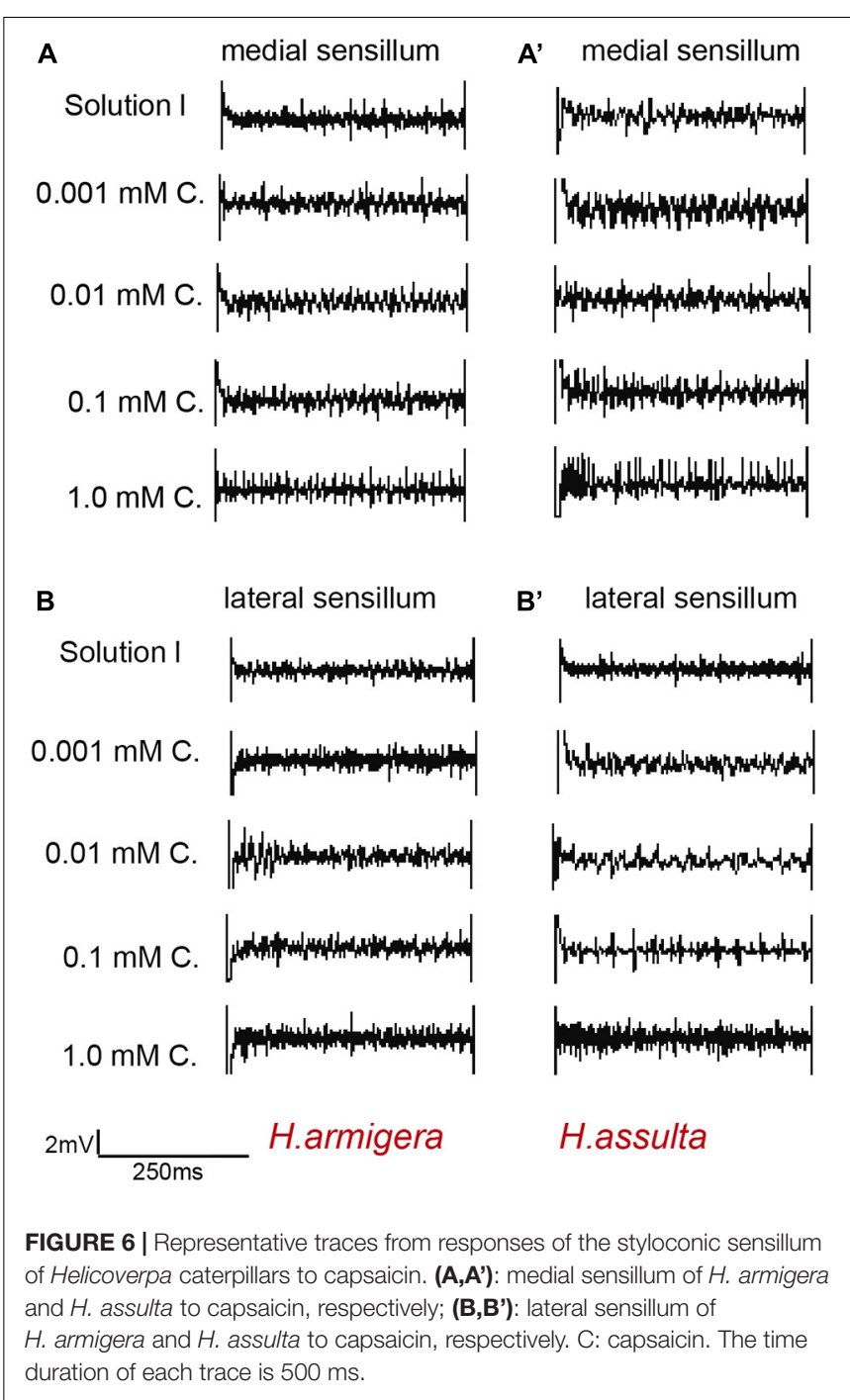


$P=0.423 ; 10 \mathrm{mM}, t(107)=-1.020, P=0.310 ; 50 \mathrm{mM}$, $t(235)=-1.223, P=0.223]$, while feeding preferences of $H$. assulta were significantly elicited at $1.0,10$, and $50 \mathrm{mM}$ [Figure 4C'; paired-sample $t$-test: $1.0 \mathrm{mM}, t(125)=-2.541$, $P=0.012 ; 10 \mathrm{mM}, t(141)=-2.252, P=0.026 ; 50 \mathrm{mM}$, $t(112)=-4.276, P<0.0001]$.

\section{Electrophysiological Responses to Secondary Metabolites}

The four investigated plant secondary metabolites induced high responses of the medial sensillum (e.g., see representative traces in Figures 5A, $\mathbf{A}^{\prime}, \mathbf{6 A}, \mathbf{A}^{\prime}$ ) compared to the relatively low responses of the lateral sensillum of the two Helicoverpa species (e.g., see traces in Figures 5B, B', 6B, B'). Three types of GRNs, in most traces, were identified in the responses of both sensilla to the four compounds, including the "S" GRNs, the "M2" GRNs, and the "L" GRNs, which best responded to water, the secondary metabolites, and salt, respectively (e.g., see representative identified GRNs in Figure 5).

In general, the responses of "M2" GRNs in both sensilla of the two Helicoverpa species induced by four secondary metabolites were high, while the responses of "S" GRNs and "L" GRNs in both sensilla induced by four secondary metabolites were relatively

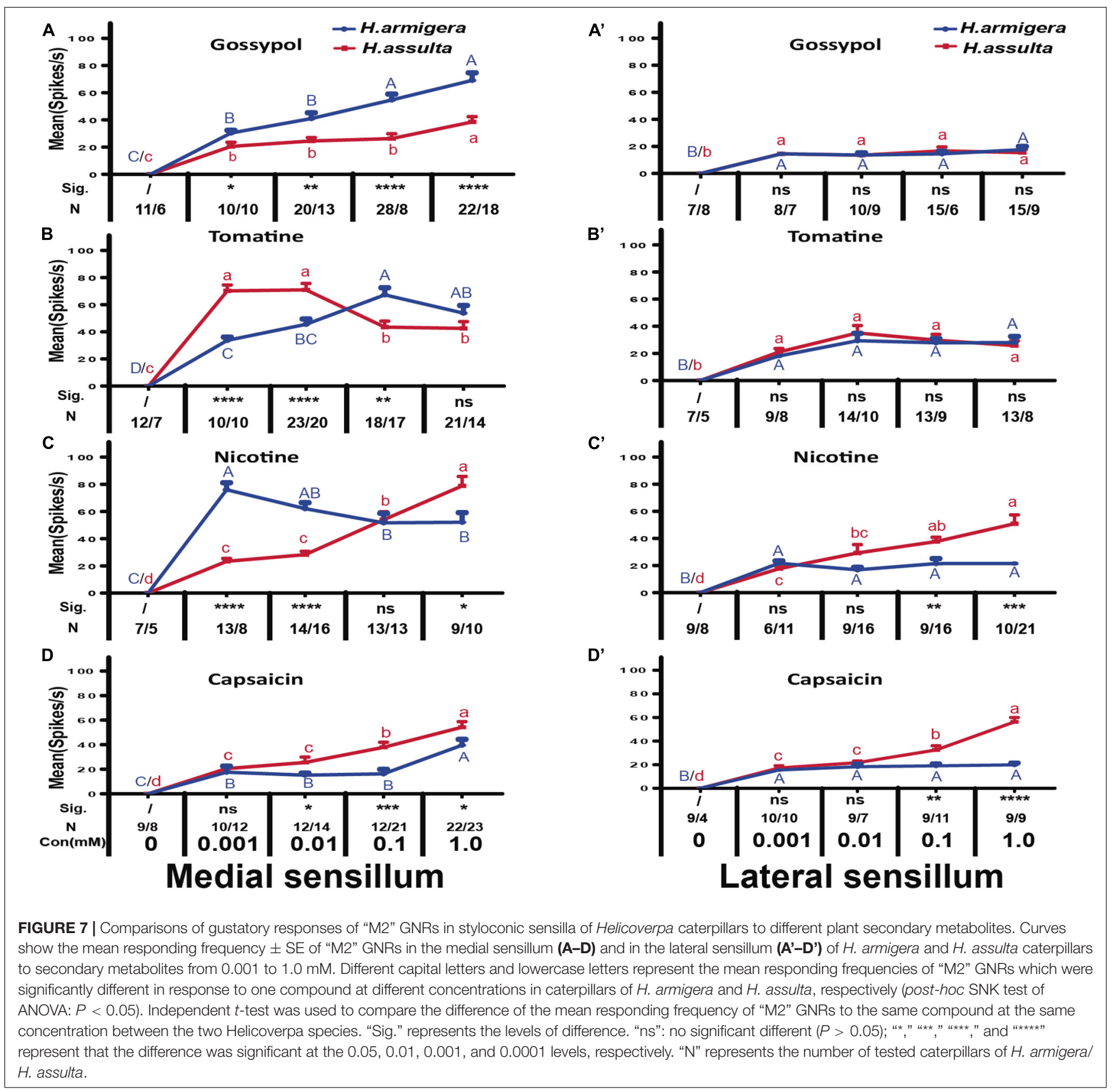


low. The responses of "M2" GRNs in the medial sensillum to each of the four plant secondary metabolites were different between the two species. Gossypol induced higher levels of response of "M2" GRNs in medial sensillum of $H$. armigera caterpillars than that of $H$. assulta (Figure 7A, independent-sample $t$-test of $0.001 \mathrm{mM}: \mathrm{df}=18, t=2.79, P=0.0121 ; 0.01 \mathrm{mM}: \mathrm{df}=31$, $t=3.19, P=0.0033 ; 0.1 \mathrm{mM}: \mathrm{df}=34, t=3.70, P=0.0001 ; 1.0 \mathrm{mM}$ : $\mathrm{df}=38, t=4.45, P=0.0001)$. Tomatine at $0.001 \mathrm{mM}$ and $0.01 \mathrm{mM}$ induced lower responses of "M2" GRNs in $H$. armigera than those in $H$. assulta caterpillars (Figure $7 \mathbf{B}$, independent-sample $t$-test of $0.001 \mathrm{mM}$ : df $=18, t=-7.65, P<0.0001 ; 0.01 \mathrm{mM}$ : $\mathrm{df}=41$, $t=-4.06, P=0.0002)$ but elicited higher levels of response at high concentration in $H$. armigera than that of $H$. assulta (Figure 7B, independent-sample $t$-test of $0.1 \mathrm{mM}$ : $\mathrm{df}=33, t=3.36, P=0.002$; $1.0 \mathrm{mM}: \mathrm{df}=33, t=1.26, P=0.2128)$.

Different from tomatine, nicotine at $0.001 \mathrm{mM}$ and $0.01 \mathrm{mM}$ induced higher levels of responses of "M2" GRNs in the medial sensillum of $H$. armigera than those of $H$. assulta (Figure 7C, independent-sample $t$-test of $0.001 \mathrm{mM}: \mathrm{df}=19, t=8.69$, $P<0.0001 ; 0.01 \mathrm{mM}: \mathrm{df}=28, t=6.91, P<0.0001)$ but elicited lower levels of response at $1.0 \mathrm{mM}$ in $H$. armigera than that of $H$. assulta caterpillars(Figure 7C, $1.0 \mathrm{mM}$ : df $=17, t=-2.88$, $P=0.0105)$. Capsaicin elicited relatively lower levels of responses of "M2" GRNs in the medial sensillum of $H$. armigera caterpillars than those of $H$. assulta caterpillars (Figure 7D, independentsample $t$-test of $0.01 \mathrm{mM}$ : $\mathrm{df}=20, t=-2.35, P=0.0271 ; 0.1 \mathrm{mM}$ : $\mathrm{df}=31, t=-4.05, P=0.0003 ; 1.0 \mathrm{mM}: \mathrm{df}=43, t=-2.33$, $P=0.0245)$.

For responses of "M2" GRNs in the lateral sensillum, it showed that gossypol and tomatine induced low and similar responses of "M2" GRNs between the two Helicoverpa species (Figure 7A' $0.001 \mathrm{mM}$ gossypol: $\mathrm{df}=13, t=0.01, P=0.99 ; 0.01 \mathrm{mM}$ gossypol: $\mathrm{df}=17, t=-0.02, P=0.98 ; 0.1 \mathrm{mM}$ gossypol: $\mathrm{df}=19, t=-0.70$, $P=0.49$; 1.0 mM gossypol: $\mathrm{df}=22, t=0.54, P=0.60$; Figure 7B', $0.001 \mathrm{mM}$ tomatine: $\mathrm{df}=15, t=-0.92, P=0.37 ; 0.01 \mathrm{mM}$ tomatine: $\mathrm{df}=22, t=-0.92, P=0.37 ; 0.1 \mathrm{mM}$ tomatine: $\mathrm{df}=20$,
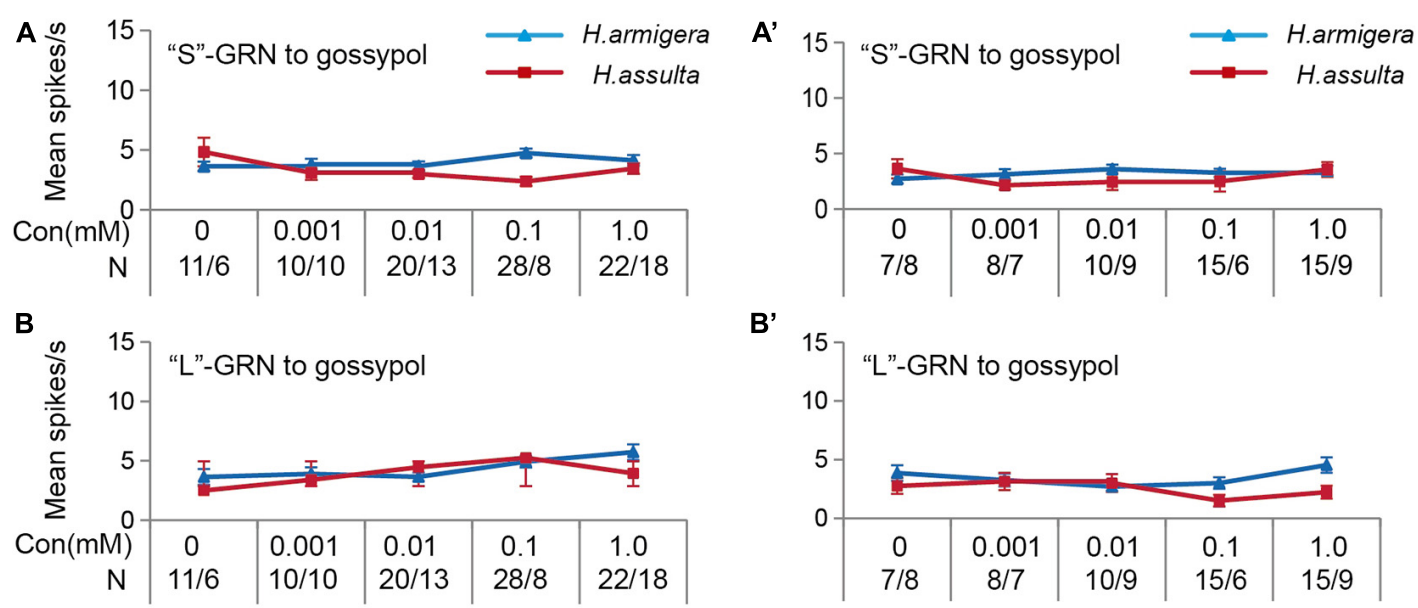

B'

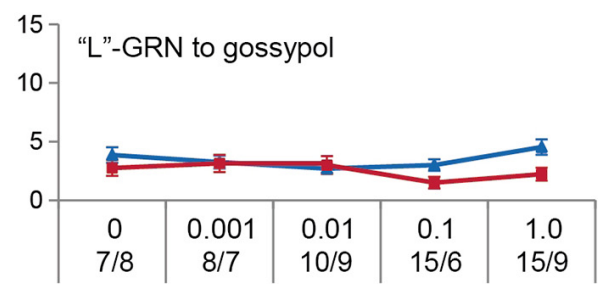

C

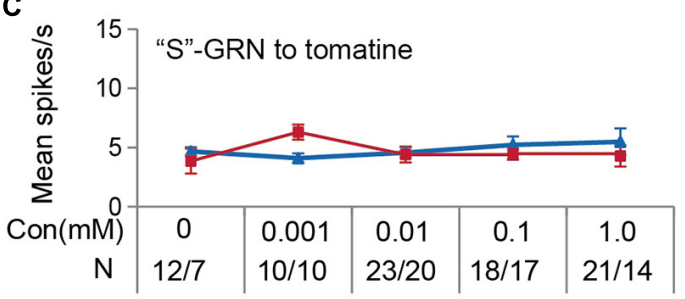

C'

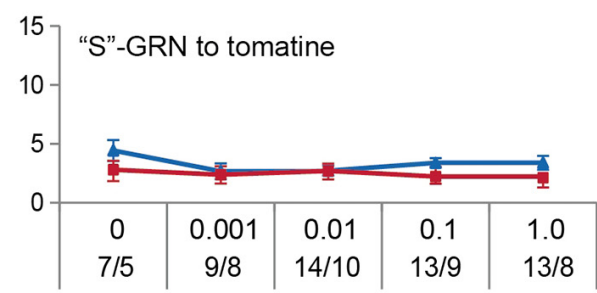

D

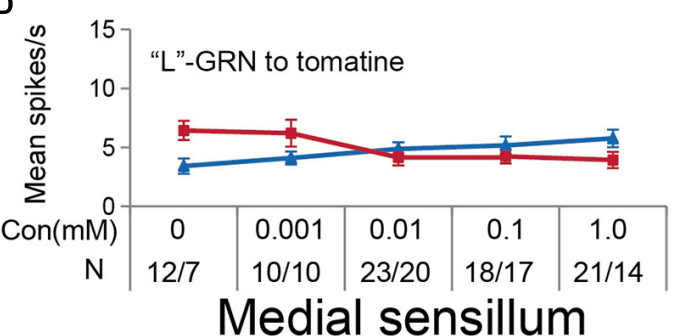

D'

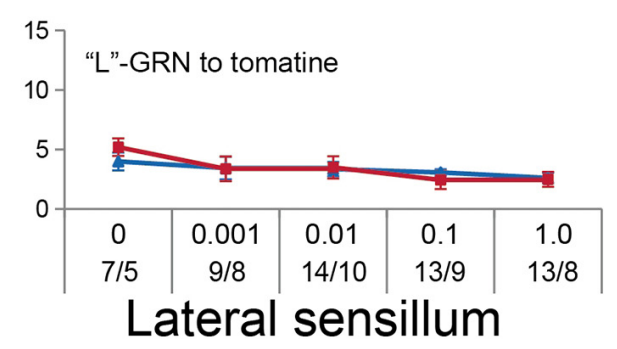

FIGURE 8 | Responses of "S" and "L" GRNs in the styloconic sensilla of Helicoverpa caterpillars to gossypol and tomatine. (A,A'): responses to gossypol of the indentified "S" GRNs from the medial and the lateral sensillum, respectively; (B,B'): responses to gossypol of the indentified " $L$ " GRNs from the medial and the lateral sensillum, respectively; (C,C'): responses to tomatine of the indentified "S" GRNs from the medial and the lateral sensillum, respectively; (D,D'): responses to tomatine of the indentified "L" GRNs from the medial and the lateral sensillum, respectively. 
$t=-0.40, P=0.69 ; 1.0 \mathrm{mM}$ tomatine: $\mathrm{df}=19, t=0.18, P=0.86)$. However, the responses of "M2" GRNs in the lateral sensillum to both nicotine and capsaicin at $0.1 \mathrm{mM}$ and $1.0 \mathrm{mM}$ were higher in $H$. assulta caterpillars than those of $H$. armigera (Figure 7C', $0.1 \mathrm{mM}$ nicotine: $\mathrm{df}=23, t=-3.30, P=0.0031 ; 1.0 \mathrm{mM}$ nicotine: $\mathrm{df}=29, t=-4.13, P=0.0004$; Figure $7 \mathrm{D}^{\prime}, 0.1 \mathrm{mM}$ capsaicin: $\mathrm{df}=18, t=-3.23, P=0.0047 ; 1.0 \mathrm{mM}$ capsaicin: $\mathrm{df}=16$, $t=-9.27, P<0.0001)$.

Four plant secondary metabolites also induced responses of "S" GRNs and "L" GRNs in both sensilla of the two Helicoverpa species. While the responses of the two GRNs to each compound were low with non-significant change among different concentrations (SNK test after ANOVA for each compound: $P>0.05$ ) (gossypol: Figures $\mathbf{8 A}, \mathbf{A}^{\prime}, \mathbf{B}, \mathbf{B}^{\prime}$; tomatine: Figures 8C,C', D,D'; nicotine: Figures 9A,A', B,B'; capsaicin: Figures 9C,C', D,D').

By comparing the responses of "M2" GRNs within one sensillum to the four secondary metabolites, it shows that the responses were significantly affected by both compounds and concentrations in either Helicoverpa species (GLM-univariate analysis of medial sensillum of $H$. armigera: compounds, $\mathrm{df}=3$, $F=39.814, P<0.0001 ;$ concentrations, $\mathrm{df}=4, F=188.576$, $P<0.0001$; compounds $\times$ concentrations, $\mathrm{df}=12, F=7.659$, $P<0.0001$; medial sensillum of $H$. assulta: compounds, $\mathrm{df}=3$, $F=19.4448, P<0.0001 ;$ concentrations, $\mathrm{df}=4, F=151.172$, $P<0.0001$; compounds $\times$ concentrations, $\mathrm{df}=12, F=17.406$,
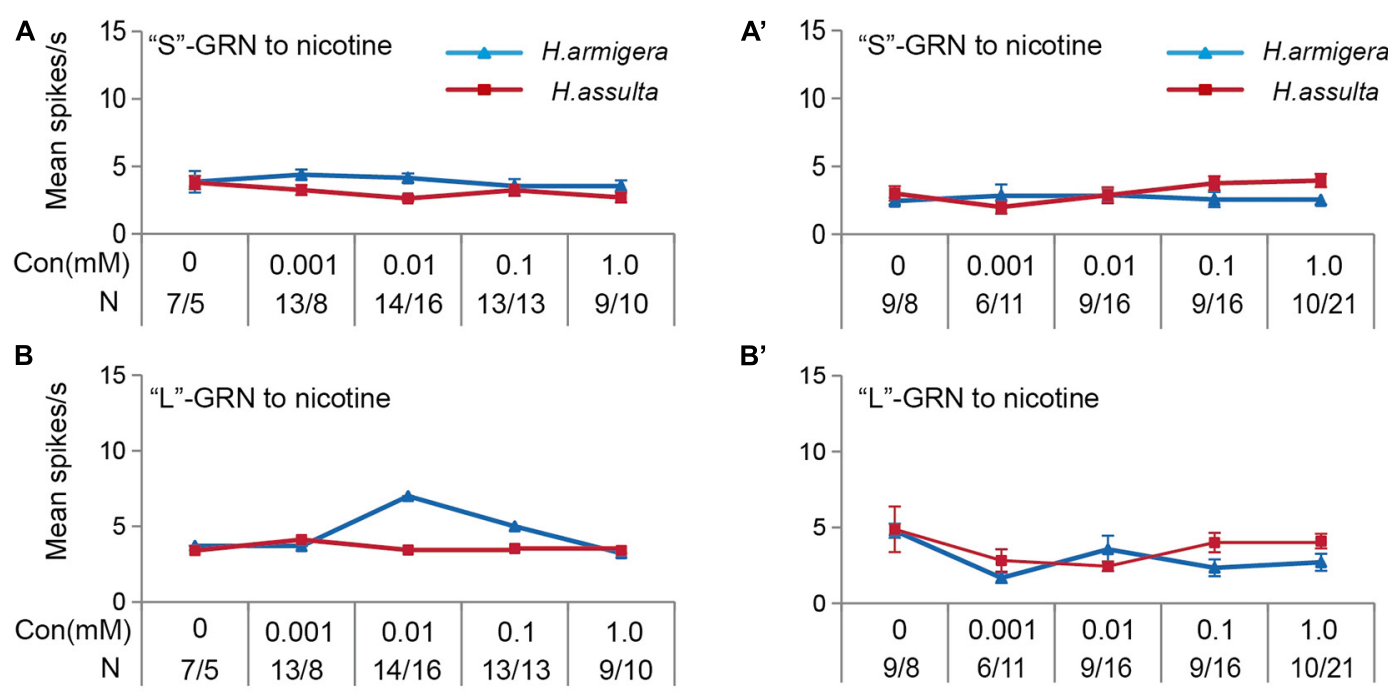

B'
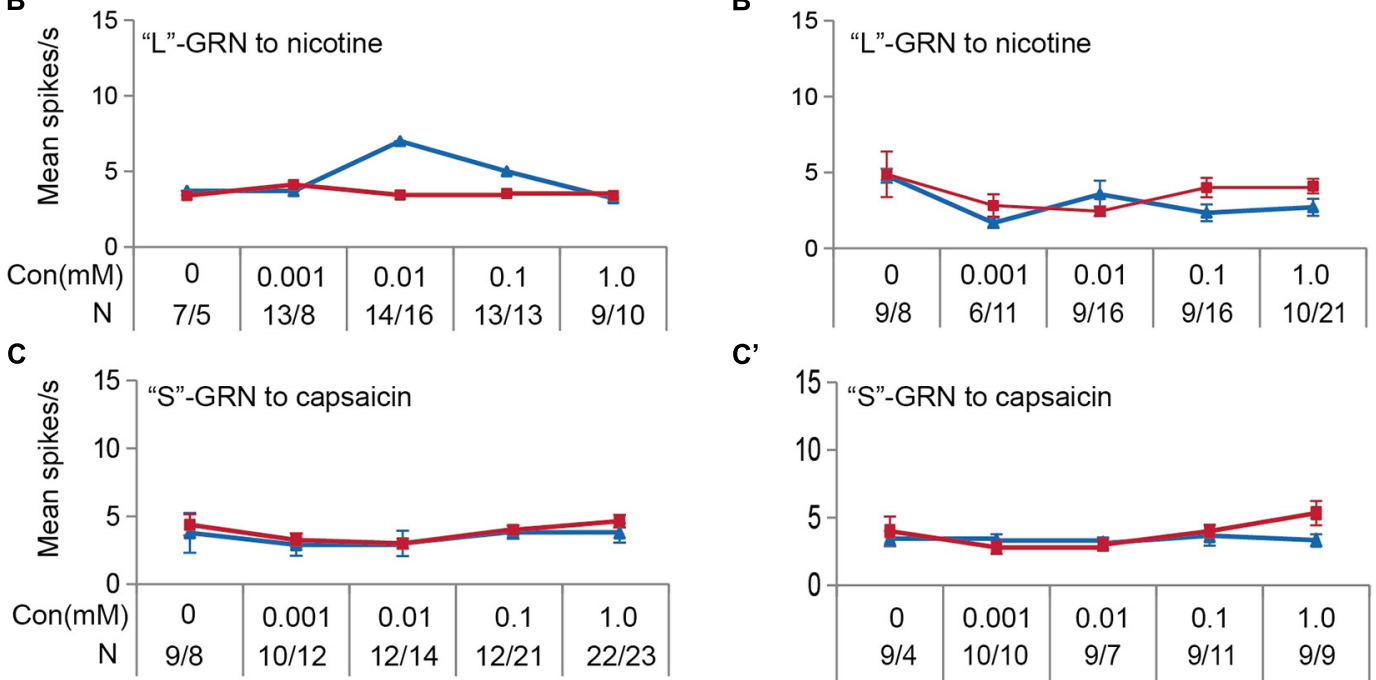

C'
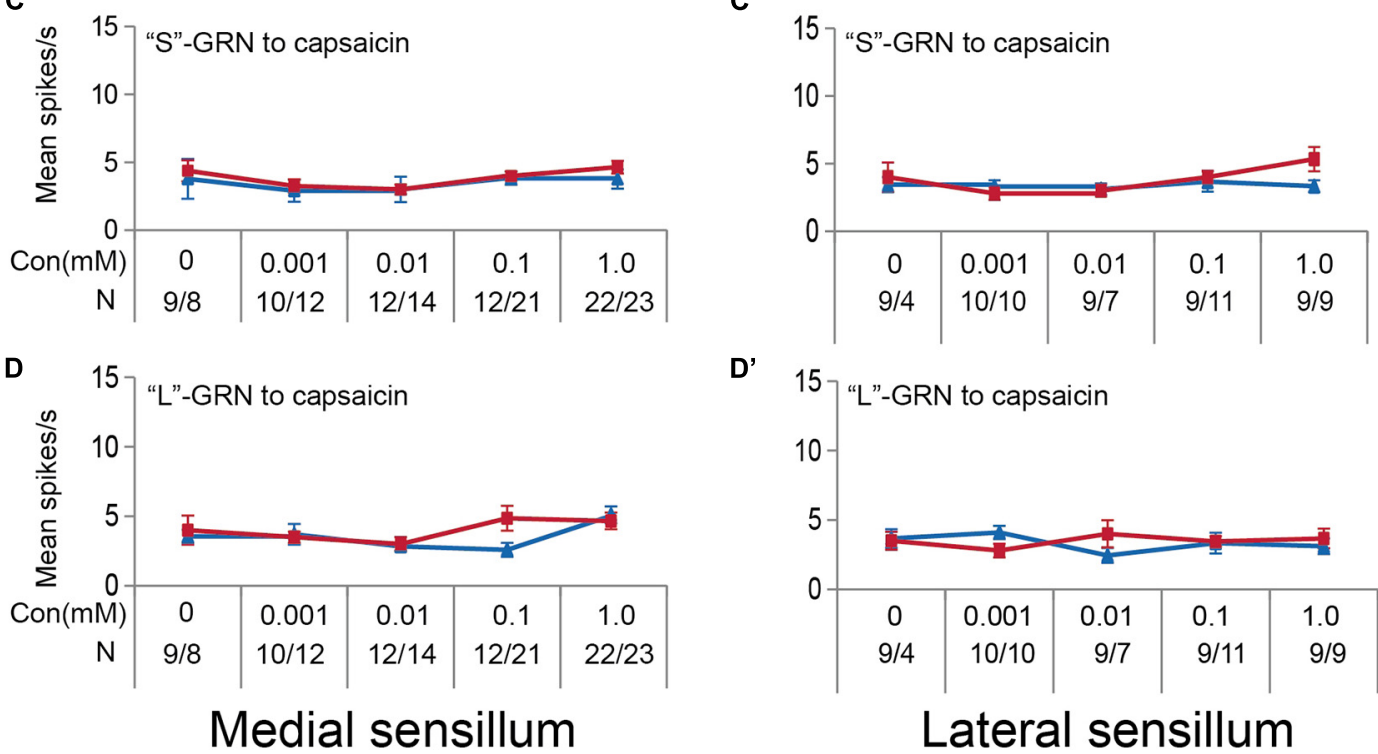

D'

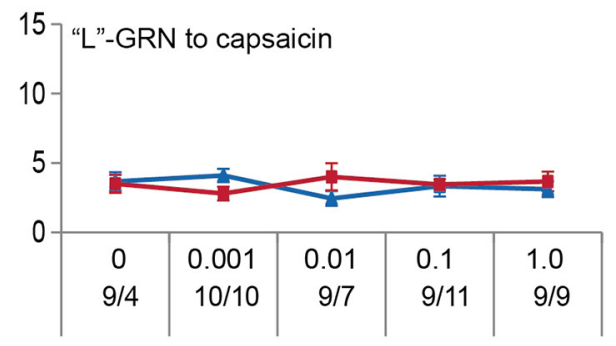

Lateral sensillum

FIGURE 9 | Responses of "S" and "L" GRNs in the styloconic sensilla of Helicoverpa caterpillars to nicotine and capsaicin. (A,A'): responses to nicotine of the indentified "S" GRNs from the medial and lateral sensillum, respectively; (B,B'): responses to nicotine of the indentified "L" GRNs from the medial and lateral sensillum, respectively; (C,C'): responses to capsaicin of the indentified "S" GRNs from the medial and the lateral sensillum, respectively; (D,D'): responses to capsaicin of the indentified "L" GRNs from the medial and the lateral sensillum, respectively. 
$P<0.0001$ ) (Table 2). However, the ranks of the general responding frequency between the two species were different. The response of "M2" GRNs in medial sensillum of $H$. armigera was the strongest to nicotine, followed by gossypol and tomatine, then low response to capsaicin (Table 3). However, for H. assulta, tomatine induced the strongest response of "M2" GRNs in the medial sensillum, followed by nicotine, capsaicin, and gossypol (Table 3). For the "M2" GRNs in the lateral sensillum between the two species, tomatine induced relatively stronger responses than those induced by gossypol, nicotine, and capsaicin in H. armigera, whereas gossypol induced the lowest responses compared to those by other three compounds in H. assulta (Table 3).

\section{Feeding Preferences for Plant Secondary Metabolites}

Gossypol at 0.1 and $1.0 \mathrm{mM}$ drove appetitive feedings in $H$. armigera caterpillars [Figure 10A; paired-sample $t$-test: $0.1 \mathrm{mM}, t(135)=-4.403, P<0.0001 ; 1.0 \mathrm{mM}, t(97)=-3.415$, $P=0.001]$, but $0.1 \mathrm{mM}$ and $1.0 \mathrm{mM}$ gossypol drove aversive feedings in $H$. assulta caterpillars [Figure 10A'; paired-sample $t$-test: $0.1 \mathrm{mM}, t(99)=3.268, P=0.001 ; 1.0 \mathrm{mM}, t(137)=2.179$, $P=0.031$. Tomatine at concentrations of 0.01 and $0.1 \mathrm{mM}$ drove appetitive feedings in $H$. armigera caterpillars [Figure 10B; paired-sample $t$-test: $0.01 \mathrm{mM}, t(103)=-2.371, P=0.02$;
$0.1 \mathrm{mM}, t(114)=-3.324, P=0.001]$, while $0.1 \mathrm{mM}$ and $1.0 \mathrm{mM}$ tomatine significantly deterred feedings of $H$. assulta caterpillars [Figure 10B'; paired-sample $t$-test: $0.1 \mathrm{mM}, t(118)=6.941$, $P<0.0001 ; 1.0 \mathrm{mM}, t(170)=9.369, P<0.0001]$.

Nicotine at the concentration of $1.0 \mathrm{mM}$ deterred feedings of $H$. armigera caterpillars [Figure 10C; paired-sample $t$-test: $1.0 \mathrm{mM}, t(98)=6.471, P<0.0001]$ but drove appetitive feedings of $H$. assulta caterpillars at concentrations of 0.1 and $1.0 \mathrm{mM}$ [Figure 10C'; paired-sample $t$-test: $0.1 \mathrm{mM}, t(101)=-7.569$, $P<0.0001 ; 1.0 \mathrm{mM}, t(110)=-2.916, P=0.004]$. Capsaicin at the concentration of $1.0 \mathrm{mM}$ significantly drove aversive feedings of $H$. armigera caterpillars [Figure 10D; one-sample $t$-test: $1.0 \mathrm{mM}$, $t(100)=2.972, P=0.004)$, while 0.01 and $0.1 \mathrm{mM}$ capsaicin significantly drove appetitive feedings of $H$. assulta caterpillars [Figure 10D'; one-sample $t$-test: $0.01 \mathrm{mM}, t(90)=-5.727$, $P<0.0001 ; 0.1 \mathrm{mM}, t(100)=-2.412, P=0.018]$.

\section{DISCUSSION}

\section{Behavioral and Gustatory Response to the Primary Metabolites}

Fructose, glucose, and proline have been widely reported to be phagostimulants for a variety of insect herbivores

TABLE 2 | Analysis of variance of the gustatory responses of "M2" GRNs in styloconic sensilla of Helicoverpa spp. partitioning effects of compounds and concentrations (GLM-Univariate analysis).

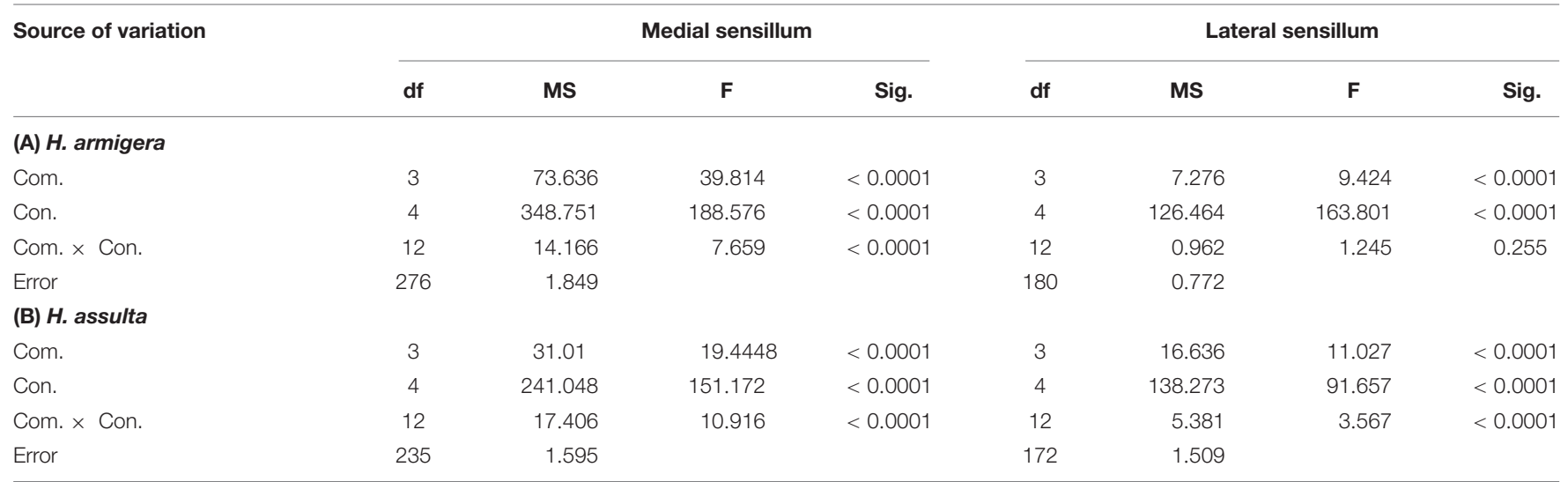

Raw data of response frequencies were square-root transformed before analysis to meet the assumptions of GLM. Com.: compounds including gossypol, tomatine, nicotine, and capsaicin. Con.: concentrations.

TABLE 3 | Multiple comparisons of gustatory responses of "M2" GRNs in styloconic sensilla of Helicoverpa spp. to different plant secondary metabolites.

\begin{tabular}{|c|c|c|c|c|}
\hline \multirow[t]{2}{*}{ Compounds } & \multicolumn{2}{|c|}{ Medial sensillum } & \multicolumn{2}{|c|}{ Lateral sensillum } \\
\hline & H. armigera & H. assulta & H. armigera & H. assulta \\
\hline Gossypol & $45.90 \pm 29.09 b$ & $28.07 \pm 19.98 d$ & $13.35 \pm 8.36 b$ & $11.87 \pm 7.92 b$ \\
\hline Tomatine & $44.36 \pm 28.21 b$ & $50.81 \pm 27.85 a$ & $23.20 \pm 16.76 \mathrm{a}$ & $24.83 \pm 15.59 a$ \\
\hline Nicotine & $53.55 \pm 29.18 \mathrm{a}$ & $40.94 \pm 28.49 b$ & $16.05 \pm 10.42 b$ & $32.44 \pm 26.03 \mathrm{a}$ \\
\hline Capsaicin & $21.92 \pm 20.52 c$ & $33.95 \pm 23.84 c$ & $14.57 \pm 8.67 b$ & $28.98 \pm 19.28 \mathrm{a}$ \\
\hline
\end{tabular}

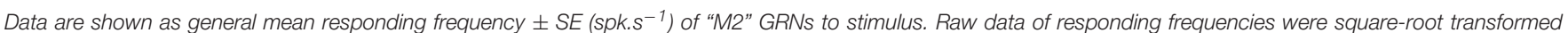

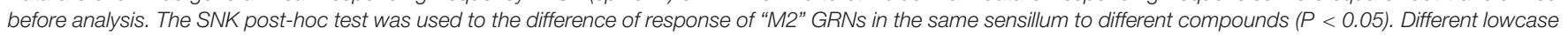
letters in a vertical column represent the difference is significant $(P<0.05)$. 


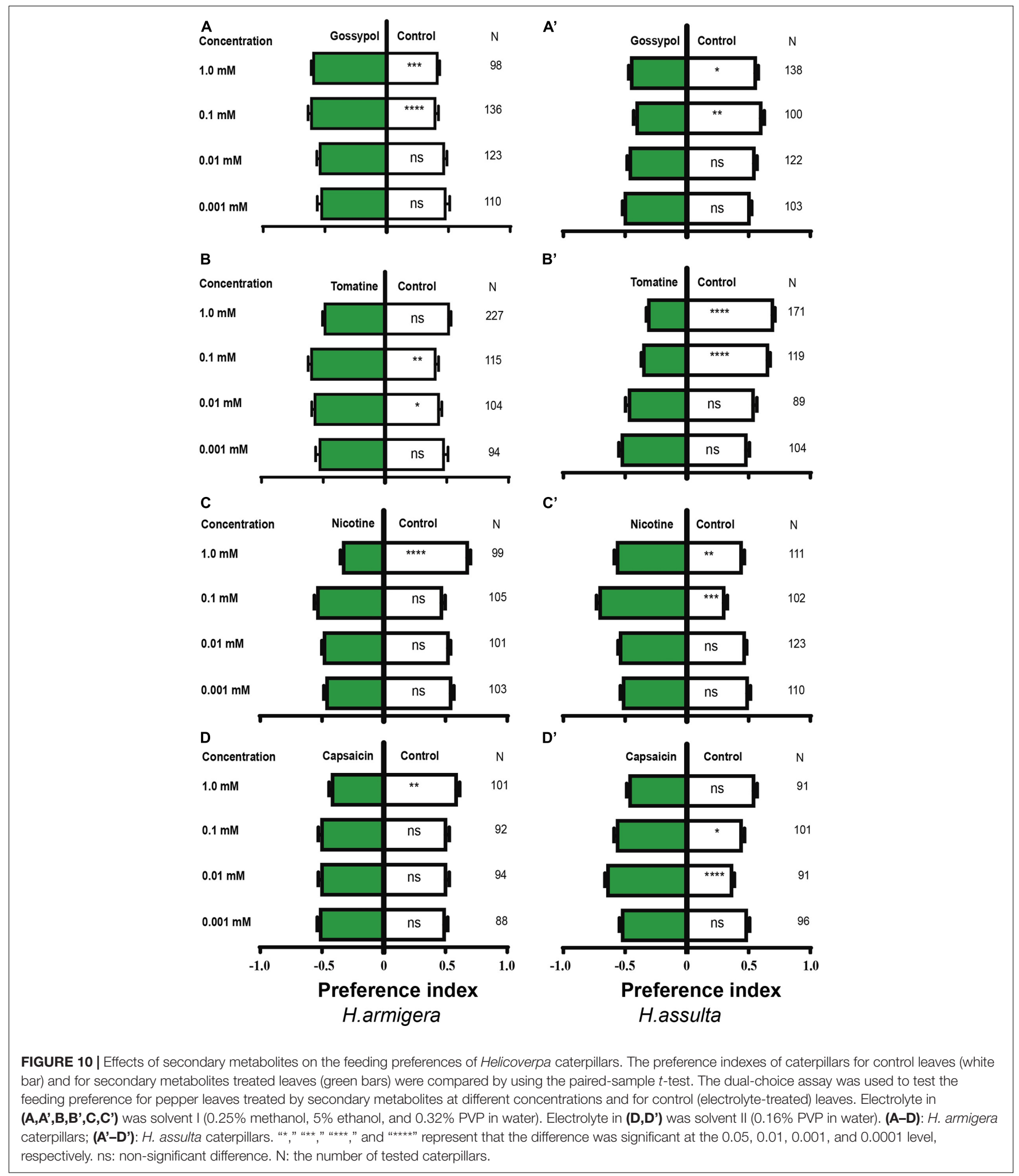

(Albert et al., 1982; Bernays and Chapman, 2001; Liscia et al., 2004; Jiang et al., 2015; Mang et al., 2016). Our present study also shows that fructose could drive appetitive feedings of caterpillars in both Helicoverpa species. Glucose and proline at the given concentrations drove appetitive feedings of $H$. assulta caterpillars but had no significant effects on the generalist species $H$. armigera, suggesting that the generalist is less sensitive to the two compounds. This result is consistent with our previous 
study that the feeding preference of $H$. armigera caterpillars is more flexible than that of $H$. assulta if caterpillars pre-exposed to different diets (Wang et al., 2017). The neural constraint hypothesis predicts that specialist herbivores always make more accurate decisions than generalists in the process of selection plants (Bernays, 1998). Our data provide further evidence that the specialist had better ability to perceive the sugars or essential nutrients than the generalist. However, our result indicated that the responding patterns of GRNs in galeal sensilla to each primary metabolite were similar between the two species, suggesting that the difference of feeding preferences should not be attributed to the firing rate of peripheral GRNs but might be from differences of the processing information within the central nervous system.

\section{Behavioral and Gustatory Response to the Secondary Metabolites}

Gossypol and tomatine are two major plant secondary metabolites from cotton and tomato, respectively, which are toxic or aversive on herbivorous insects (Vickerman and de Boer, 2002; Mulatu et al., 2006; Arnason and Bernards, 2010; Carriere et al., 2019). Our results also show that the two compounds drove aversive feedings of the specialist $H$. assulta, but caterpillars of the generalist $H$. armigera exhibited appetitive feedings for the two secondary metabolites. Such kind of secondary metabolites drove appetitive feedings of the generalist herbivores; to our knowledge, they have not been reported to date. We postulate that it should be attributed to the extraordinary adaptive capacity of caterpillars of $H$. armigera to the two compounds, for example, the tolerance and detoxifying metabolism (Mao et al., 2007; Zhou et al., 2010; Bretschneider et al., 2016; Krempl et al., 2016), while caterpillars of the specialist $H$. assulta do not feed on cotton and tomato plants in nature (Mitter et al., 1993) and exhibit aversive responses to the two secondary metabolites.

Nicotine (Szentesi and Bernays, 1984; Shields et al., 2008; Hori et al., 2011; Sollai et al., 2015) and capsaicin (Cowles et al., 1989; Hori et al., 2011; Li et al., 2020) have been generally reported as feeding deterrents for herbivorous insects. However, our results demonstrate that the two solanaceous alkaloids elicited appetitive feedings of the specialist $H$. assulta, while they drove aversive feedings of the generalist $H$. armigera. We also postulate that it could be attributed to the specialist $H$. assulta being more adaptive to the two alkaloids than the generalist $H$. armigera. Firstly, it is known that tobacco and hot pepper are two limited host plants of the specialist $H$. assulta (Mitter et al., 1993), while the generalists have to deal with lots of toxic plant metabolites based on the neural-constraint hypothesis (Levins and Macarthur, 1969; Bernays and Wcislo, 1994; Bernays and Funk, 1999). Secondly, the adaptations of specialists to nicotine and tobacco plants have been well reported on caterpillars of the tobacco cutworm Manduca sexta (Snyder et al., 1993; Glendinning, 2002; Wink and Theile, 2002; Govind et al., 2010; Kumar et al., 2014). For capsaicin, it has been found that the larval development of $H$. assulta could benefit from the dietary capsaicin compared to the negative effects on
H. armigera (Ahn et al., 2011; Jia et al., 2012). At the level of metabolism, the capacity of degrading the capsaicinoids in $H$. assulta was overall higher than that in $H$. armigera (Zhu et al., 2020). Then, our data provide further evidence of adaptation of the specialist $H$. assulta to the toxic plant metabolites at the behavioral and chemosensory levels, which is similar to the attractive effects of "token stimuli," the specific secondary metabolites from host plants, on other investigated specialist herbivores (Renwick and Lopez, 1999; del Campo et al., 2001; Miles et al., 2005; Sollai et al., 2018).

For the response of galeal sensilla to the four secondary metabolites, it also indicates that each of the four secondary metabolites stimulated different responding patterns of GRNs between the two closely related species. Combining the differences of feeding preferences with the taste response of GRNs of the two species, it suggests that the activities of peripheral GRNs to the four alkaloids could contribute to the difference of feeding behaviors between the two Helicoverpa species. Therefore, it seems that the neural coding for behavioral decisions of the investigated secondary metabolites in the two Helicoverpa species is different from that for behavioral decisions of the primary metabolites. The present results suggest that the two Helicoverpa species evaluate the plant primary metabolites differently at the CNS level, while they evaluate the secondary metabolites differently at both peripheral and central levels.

\section{CONCLUSION}

In conclusion, our present results show that the difference of both behavioral feedings and electrophysiological responses to plant metabolites between the two Helicoverpa species could contribute to the difference of diet breadth in the two species. Especially, it indicates that caterpillars of the specialist $H$. assulta preferred more to glucose and proline than the generalist $H$. armigera, suggesting that specialist herbivores are more efficient in finding food sources than generalists. More interestingly, gossypol and tomatine, the two secondary metabolites from host plants of the generalist, could drive appetitive feedings of this insect species, suggesting that generalist insects adapt not only to toxic secondary metabolites at metabolism level but also at the behavioral and chemosensory levels.

We also found that nicotine and capsaicin, the secondary metabolites from two limited host plants of the specialist $H$. assulta, could drive appetitive feedings of this insect herbivore, suggesting that this specialist also has adapted to its host plants at behavioral and gustatory levels. However, it is not clear why the generalist $H$. armigera did not prefer nicotine and capsaicin since tobacco and hot pepper plants are also the host plants of this generalist species. We postulate that it may be related to the host plant shifts, host adaptations, fitness costs, and evolutionary pressures during the evolution between Helicoverpa species and their host plants. Regardless, our finding would give a new insight of underscoring the adaptation of generalist insects to its host plant. In addition, in future work, the ecological context of the evolution and the further adaptation mechanisms of $H$. armigera to these compounds should be addressed. 


\section{DATA AVAILABILITY STATEMENT}

The original contributions presented in the study are included in the article/supplementary material, further inquiries can be directed to the corresponding author/s.

\section{AUTHOR CONTRIBUTIONS}

QT, WH, and YM conceived the experiment. LS, WH, and JZ conducted the experiment. QT, LS, and XZ wrote the manuscript. LS, QT, and WH analyzed the data. YM, YD, and QY edited the manuscript. All authors read and approved the final manuscript.

\section{REFERENCES}

Ahn, S. J., Badenes-Perez, F. R., and Heckel, D. G. (2011). A host-plant specialist, Helicoverpa assulta, is more tolerant to capsaicin from Capsicum annuum than other noctuid species. J. Insect Physiol. 57, 1212-1219. doi: 10.1016/j.jinsphys. 2011.05.015

Albert, P. J., Charley, C., Hanson, F., and Parisella, S. (1982). Feeding responses of eastern spruce budworm larvae to sucrose and other carbohydrates. J. Chem. Ecol. 8, 233-239. doi: 10.1007/BF00984019

Arnason, J. T., and Bernards, M. A. (2010). Impact of constitutive plant natural products on herbivores and pathogens. Can. J. Zool. 88, 615-627. doi: 10.1139/ Z10-038

Barbour, J. D., and Kennedy, G. G. (1991). Role of steroidal glycoalkaloid alphatomatine in host-plant resistance of tomato to colorado potato beetle. J. Chem. Ecol. 17, 989-1005. doi: 10.1007/BF01395604

Behmer, S. T., Elias, D. O., and Bernays, E. A. (1999). Post-ingestive feedbacks and associative learning regulate the intake of unsuitable sterols in a generalist grasshopper. J. Exp. Biol. 202(Pt 6), 739-748. doi: 10.1080/106351599260508

Bernays, E. A. (1998). The value of being a resource specialist: behavioral support for a neural hypothesis. Am. Nat. 151, 451-464. doi: 10.1086/286132

Bernays, E. A., and Chapman, R. F. (2001). Taste cell responses in the polyphagous arctiid, Grammia geneura: towards a general pattern for caterpillars. J. Insect Physiol. 47, 1029-1043. doi: 10.1016/s0022-1910(01)00079-8

Bernays, E. A., Chapman, R. F., and Singer, M. S. (2000a). Sensitivity to chemically diverse phagostimulants in a single gustatory neuron of a polyphagous caterpillar. J. Comp. Physiol. A 186, 13-19. doi: 10.1007/s003590050002

Bernays, E. A., and Funk, D. J. (1999). Specialists make faster decisions than generalists: experiments with aphids. Proc. R. Soc. Biol. Sci. Ser. B 266:151. doi: $10.1098 /$ rspb.1999.0615

Bernays, E. A., Oppenheim, S., Chapman, R. F., Kwon, H., and Gould, F. (2000b). Taste sensitivity of insect herbivores to deterrents is greater in specialists than in generalists: a behavioral test of the hypothesis with two closely related caterpillars. J. Chem. Ecol. 26, 547-563. doi: 10.1023/A:1005430010314

Bernays, E. A., and Wcislo, W. T. (1994). Sensory capabilities, information processing, and resource specialization. Q. Rev. Biol. 69, 187-204. doi: 10.1086/ 418539

Bretschneider, A., Heckel, D. G., and Vogel, H. (2016). Know your ABCs: characterization and gene expression dynamics of $\mathrm{ABC}$ transporters in the polyphagous herbivore Helicoverpa armigera. Insect Biochem. Mol. Biol. 72, 1-9. doi: 10.1016/j.ibmb.2016.03.001

Carriere, Y., Yelich, A. J., Degain, B., Harpold, V. S., Unnithan, G. C., Kim, J. H., et al. (2019). Gossypol in cottonseed increases the fitness cost of resistance to Bt cotton in pink bollworm. Crop Prot. 126:104914. doi: 10.1016/J.Cropro.2019. 104914

Cowles, R. S., Keller, J. E., and Miller, J. R. (1989). Pungent spices, ground red pepper, and synthetic capsaicin as onion fly ovipositional deterrents. J. Chem. Ecol. 15, 719-730. doi: 10.1007/BF01014714

del Campo, M. L., Miles, C. I., Schroeder, F. C., Mueller, C., Booker, R., and Renwick, J. A. (2001). Host recognition by the tobacco hornworm is mediated

\section{FUNDING}

The work was supported by the National Natural Science Foundation of China (Grant Nos. 31672367 and 31861133019) and the Key Scientific and Technological Project of Henan Province (202102110072). The funders had no role in the study design, data collection and analysis, decision to publish, or preparation of the manuscript.

\section{ACKNOWLEDGMENTS}

We thank Mr. Zhongwei Sun for kindly helping in supplying the pepper seedlings.

by a host plant compound. Nature 411, 186-189. doi: 10.1038/35075559 35075559

Fitt, G. P. (1989). The ecology of Heliothis species in relation to agroecosystems. Annu. Rev. Entomol. 34, 17-52. doi: 10.1146/annurev.en.34.010189.00 0313

Glendinning, J. I. (2002). How do herbivorous insects cope with noxious secondary plant compounds in their diet? Entomol. Exp. Appl. 104, 15-25. doi: 10.1046/j. 1570-7458.2002.00986.x

Govind, G., Mittapalli, O., Griebel, T., Allmann, S., Bocker, S., and Baldwin, I. T. (2010). Unbiased transcriptional comparisons of generalist and specialist herbivores feeding on progressively defenseless Nicotiana attenuata plants. PLoS One 5:e8735. doi: 10.1371/journal.pone.0008735

Hori, M., Nakamura, H., Fujii, Y., Suzuki, Y., and Matsuda, K. (2011). Chemicals affecting the feeding preference of the Solanaceae-feeding lady beetle Henosepilachna vigintioctomaculata (Coleoptera: Coccinellidae). J. Appl. Entomol. 135, 121-131. doi: 10.1111/j.1439-0418.2010.01519.x

Jermy, T. (1966). Feeding inhibitors and food preference in chewing phytophagous insects. Entomol. Exp. Appl. 9, 1-12. doi: 10.1111/j.1570-7458.1966.tb00973.x

Jia, Y., Cheng, X., Cai, Y., Luo, M., and Guo, X. (2012). Difference of the fitness of Helicoverpa armigera (Hübner) fed with different pepper varieties. Acta Ecol. Sin. 32, 159-167.

Jiang, J., Ding, S., Zhang, Y., and Wang, Y. (2010). Effects of artificial diet on the growth \& development and fecundity of H. armigera. J. Henan Agr. Univ. 44, 78-82. doi: 10.16445/j.cnki.1000-2340.2010.01.007

Jiang, X., Ning, C., Guo, H., Jia, Y., Huang, L., Qu, M., et al. (2015). A gustatory receptor tuned to $\mathrm{D}$-fructose in antennal sensilla chaetica of Helicoverpa armigera. Insect Biochem. Mol. Biol. 60, 39-46. doi: 10.1016/j.ibmb.2015.03.002

Krempl, C., Sporer, T., Reichelt, M., Ahn, S. J., Heidel-Fischer, H., Vogel, H., et al. (2016). Potential detoxification of gossypol by UDP-glycosyltransferases in the two Heliothine moth species Helicoverpa armigera and Heliothis virescens. Insect Biochem. Mol. Biol. 71, 49-57. doi: 10.1016/j.ibmb.2016.02.005

Kumar, P., Rathi, P., Schottner, M., Baldwin, I. T., and Pandit, S. (2014). Differences in ncotine metabolism of two Nicotiana attenuata herbivores render them differentially susceptible to a common native predator. PLoS One 9:e95982. doi: 10.1371/journal.pone.0095982

Levins, R., and Macarthur, R. (1969). An hypothesis to explain the incidence of monophagy. Ecology 50, 910-911. doi: 10.2307/1933709

Li, Y., Bai, P., Wei, L., Kang, R., Chen, L., Zhang, M., et al. (2020). Capsaicin functions as Drosophila ovipositional repellent and causes intestinal dysplasia. Sci. Rep. 10:9963. doi: 10.1038/s41598-020-66900-2

Liscia, A., Masala, C., Crnjar, R., Sollai, G., and Solari, P. (2004). Saccharin stimulates the "deterrent" cell in the blowfly: behavioral and electrophysiological evidence. Physiol. Behav. 80, 637-646. doi: 10.1016/j.physbeh.2003.11.002

Liu, Z., Scheirs, J., and Heckel, D. G. (2012). Trade-offs of host use between generalist and specialist Helicoverpa sibling species: adult oviposition and larval performance. Oecologia 168, 459-469. doi: 10.1007/s00442-011-2103-0

Ma, Y., Li, J. J., Tang, Q. B., Zhang, X. N., Zhao, X. C., Yan, F. M., et al. (2016). Trans-generational desensitization and within-generational resensitization of 
a sucrose-best neuron in the polyphagous herbivore Helicoverpa armigera (Lepidoptera: Noctuidae). Sci. Rep. 6:39358. doi: 10.1038/srep39358

Mang, D., Shu, M., Tanaka, S., Nagata, S., Takada, T., Endo, H., et al. (2016). Expression of the fructose receptor BmGr9 and its involvement in the promotion of feeding, suggested by its co-expression with neuropeptide F1 in Bombyx mori. Insect Biochem. Mol. Biol. 75, 58-69. doi: 10.1016/j.ibmb.2016. 06.001

Mao, Y. B., Cai, W. J., Wang, J. W., Hong, G. J., Tao, X. Y., Wang, L. J., et al. (2007). Silencing a cotton bollworm P450 monooxygenase gene by plant-mediated RNAi impairs larval tolerance of gossypol. Nat. Biotechnol. 25, 1307-1313. doi: $10.1038 /$ nbt1352

Miles, C. I., del Campo, M. L., and Renwick, J. A. (2005). Behavioral and chemosensory responses to a host recognition cue by larvae of Pieris rapae. J. Comp. Physiol. A 191, 147-155. doi: 10.1007/s00359-004-0580-x

Mitter, C., Poole, R. W., and Matthews, M. (1993). Biosystematics of the Heliothinae (Lepidoptera: Noctuidae). Annu. Rev. Entomol. 38, 207-225. doi: 10.1146/ annurev.en.38.010193.001231

Montandon, R., Stipanovic, R. D., Williams, H. J., Sterling, W. L., and Vinson, S. B. (1987). Nutritional indices and excretion of gossypol by Alabama argillacea (Hübner) and Heliothis virescens (F.) (Lepidoptera: Noctuidae) fed glanded and glandless cotyledonary cotton leaves. J. Econ. Entomol. 80, 32-36. doi: 10.1093/jee/80.1.32

Mulatu, B., Applebaum, S. W., Kerem, Z., and Coll, M. (2006). Tomato fruit size, maturity and alpha-tomatine content influence the performance of larvae of potato tuber moth Phthorimaea operculella (Lepidoptera: Gelechiidae). Bull. Entomol. Res. 96, 173-178. doi: 10.1079/ber2005412

Oliver, B. F., Maxwell, F. G., and Jenkins, J. N. (1970). Utilization of glanded and glandless cotton diets by the bollworm. J. Econ. Entomol. 63, 1965-1966. doi: 10.1093/jee/63.6.1965

Pearson, D. E., Valliant, M., Carlson, C., Thelen, G. C., Ortega, Y. K., Orrock, J. L., et al. (2019). Spicing up restoration: can chili peppers improve restoration seeding by reducing seed predation? Restor. Ecol. 27, 254-260. doi: 10.1111/rec. 12862

Renwick, J. A. (2001). Variable diets and changing taste in plant-insect relationships. J. Chem. Ecol. 27, 1063-1076. doi: 10.1023/A:1010381509601

Renwick, J. A., and Lopez, K. (1999). "Experience-based food consumption by larvae of Pieris rapae: addiction to glucosinolates?", in Proceedings of the 10th International Symposium on Insect-Plant Relationships, Vol. 56, eds S. Simpson, A. J. Mordue, and J. Hardie (Dordrecht: Springer Netherlands), 51-58. doi: 10.1046/j.1570-7458.1999.00465.x

Roessingh, P., Hora, K. H., van Loon, J. J. A., and Menken, S. B. J. (1999). Evolution of gustatory sensitivity in Yponomeuta caterpillars: sensitivity to the stereoisomers dulcitol and sorbitol is localised in a single sensory cell. J. Comp. Physiol. A 184, 119-126. doi: 10.1007/s003590050311

Schoonhoven, L. M. (1967). Chemoreception of mustard oil glucosides in larvae of Pieris brassicae. P. Koninkl. Nederl. Akad. Wetensehappen, Amsterdam. Series C 70, 556-568.

Sheck, A. L., and Gould, F. (1996). The genetic basis of differences in growth and behavior of specialist and generalist herbivore species: selection on hybrids of Heliothis virescens and H. subflexa (Lepidoptera). Evolution 50, 831-841. doi: 10.1111/j.1558-5646.1996.tb03892.x

Shields, V. D., Smith, K. P., Arnold, N. S., Gordon, I. M., Shaw, T. E., and Waranch, D. (2008). The effect of varying alkaloid concentrations on the feeding behavior of gypsy moth larvae, Lymantria dispar (L.) (Lepidoptera: Lymantriidae). Arthropod Plant Interact. 2, 101-107. doi: 10.1007/s11829-008-9035-6

Simões, P. M. V., Ott, S. R., and Niven, J. E. (2012). A long-latency aversive learning mechanism enables locusts to avoid odours associated with the consequences of ingesting toxic food. J. Exp. Biol. 215(Pt 10), 1711-1719. doi: 10.1242/jeb. 068106

Snyder, M., Hsu, E.-L., and Feyereisen, R. (1993). Induction of cytochrome P-450 activities by nicotine in the tobacco hornworm, Manduca sexta. J. Chem. Ecol. 19, 2903-2916. doi: 10.1007/BF00980591

Sollai, G., Biolchini, M., and Crnjar, R. (2018). Taste sensitivity and divergence in host plant acceptance between adult females and larvae of Papilio hospiton. Insect Sci. 25, 809-822. doi: 10.1111/1744-7917.12581

Sollai, G., and Crnjar, R. (2019). The contribution of gustatory input to larval acceptance and female oviposition choice of potential host plants in Papilio hospiton (Gene). Arch. Insect Biochem. Physiol. 100:e21521. doi: 10.1002/arch. 21521

Sollai, G., Tomassini Barbarossa, I., Masala, C., Solari, P., and Crnjar, R. (2014). Gustatory sensitivity and food acceptance in two phylogenetically closely related papilionid species: Papilio hospiton and Papilio machaon. PLoS One 9:e100675. doi: 10.1371/journal.pone.0100675

Sollai, G., Tomassini Barbarossa, I., Solari, P., and Crnjar, R. (2015). Taste discriminating capability to different bitter compounds by the larval styloconic sensilla in the insect herbivore Papilio hospiton (Gene). J. Insect Physiol. 74, 45-55. doi: 10.1016/j.jinsphys.2015.02.004

Sun, Z. X., Shi, Q., Li, Q. L., Wang, R. M., Xu, C. C., Wang, H. H., et al. (2019). Identification of a cytochrome P450 CYP6AB60 gene associated with tolerance to multi-plant allelochemicals from a polyphagous caterpillar tobacco cutworm (Spodoptera litura). Pestic. Biochem. Physiol. 154, 60-66. doi: 10.1016/j.pestbp. 2018.12.006

Szentesi, A., and Bernays, E. A. (1984). A study of behavioural habituation to a feeding deterrent in nymphs of Schistocerca gregaria. Physiol. Entomol. 9, 329-340. doi: 10.1111/j.1365-3032.1984.tb00714.x

Tang, Q., Hong, Z., Cao, H., Yan, F., and Zhao, X. (2015). Characteristics of morphology, electrophysiology, and central projections of two sensilla styloconica in Helicoverpa assulta larvae. Neuroreport 26, 703-711. doi: 10. 1097/WNR.0000000000000413

Tang, Q., Huang, L., Wang, C., Zhan, H., and van Loon, J. J. A. (2014). Inheritance of electrophysiological responses to leaf saps of host- and nonhost plants in two Helicoverpa species and their hybrids. Arch. Insect Biochem. Physiol. 86, 19-32. doi: 10.1002/arch.21154

Tang, Q., Jiang, J., Yan, Y., van Loon, J. J. A., and Wang, C. (2006). Genetic analysis of larval host-plant preference in two sibling species of Helicoverpa. Entomol. Exp. Appl. 118, 221-228. doi: 10.1111/j.1570-7458.2006.00387.x

Tao, X., Xue, X., Huang, Y., Chen, X., and Mao, Y. (2012). Gossypol-enhanced P450 gene pool contributes to cotton bollworm tolerance to a pyrethroid insecticide. Mol. Ecol. 21, 4371-4385. doi: 10.1111/j.1365-294X.2012.05548.x

Thompson, J. D. (1991). Phenotypic plasticity as a component of evolutionary change. Trends. Ecol. Evol. 6, 246-249. doi: 10.1016/0169-5347(91)90070-E

Tian, K., Zhu, J., Li, M., and Qiu, X. H. (2019). Capsaicin is efficiently transformed by multiple cytochrome P450s from Capsicum fruit-feeding Helicoverpa armigera. Pestic. Biochem. Physiol. 156, 145-151. doi: 10.1016/j.pestbp.2019. 02.015

van Loon, J. J. A. (1990). Chemoreception of phenolic acids and flavonoids in larvae of two species of Pieris. J. Comp. Physiol. A 166, 889-899. doi: 10.1007/ bf00187336

Vickerman, D. B., and de Boer, G. (2002). Maintenance of narrow diet breadth in the monarch butterfly caterpillar: response to various plant species and chemicals. Entomol. Exp. Appl. 104, 255-269. doi: 10.1046/j.1570-7458.2002. 01012.x

Wada-Katsumata, A., Silverman, J., and Schal, C. (2013). Changes in taste neurons support the emergence of an adaptive behavior in cockroaches. Science 340, 972-975. doi: 10.1126/science. 1234854

Wang, C., and Dong, J. (2001). Interspecific hybridization of Helicoverpa armigera and H. assulta (Lepidoptera: Noctuide). Chin. Sci. Bull. 46, 489-491. doi: 10.1007/bf03187264

Wang, Y., Ma, Y., Zhou, D., Gao, S., Zhao, X., Tang, Q., et al. (2017). Higher plasticity in feeding preference of a generalist than a specialist: experiments with two closely related Helicoverpa species. Sci. Rep. 7:17876. doi: 10.1038/s41598017-18244-7

Wink, M., and Theile, V. (2002). Alkaloid tolerance in Manduca sexta and phylogenetically related sphingids (Lepidoptera : Sphingidae). Chemoecology 12, 29-46. doi: 10.1007/s00049-002-8324-2

Wright, G. A., Mustard, J. A., Simcock, N. K., Ross-Taylor, A. A., McNicholas, L. D., Popescu, A., et al. (2010). Parallel reinforcement pathways for conditioned food aversions in the honeybee. Curr. Biol. 20, 2234-2240. doi: 10.1016/j.cub.2010. 11.040

Wu, K., and Gong, P. (1997). A new and practical artificial diet for the cotton bollworm. Insect Sci 4, 277-282. doi: 10.1111/j.1744-7917.1997.tb00101.x

Wu, K., Gong, P., and Li, X. (1990). Studies on artificial diets for rearing the tobacco budworm Heliothis assulta (Guenée). Acta Entomol. Sin. 33, 301-308. doi: 10.16380/j.kcxb.1990.03.007 
Yang, L., Wang, X., Bai, S., Li, X., Gu, S., Wang, C. Z., et al. (2017). Expressional divergence of insect GOX genes: from specialist to generalist glucose oxidase. J. Insect Physiol. 100, 21-27. doi: 10.1016/j.jinsphys.2017. 05.003

Zalucki, M. P., Daglish, G., Firempong, S., and Twine, P. H. (1986). The biology and ecology of Heliothis armigera (Hübner) and H. punctigera Wallengren (Lepidoptera:Noctuidae) in Australia - What do we know? Aust. J. Zool. 34, 779-814. doi: 10.1071/ZO9860779

Zhou, X., Sheng, C., Li, M., Wan, H., Liu, D., and Qiu, X. (2010). Expression responses of nine cytochrome $\mathrm{P} 450$ genes to xenobiotics in the cotton bollworm Helicoverpa armigera. Pestic. Biochem. Physiol. 97, 209-213. doi: 10.1016/j. pestbp.2010.02.003

Zhu, J., Tian, K., Reilly, C. A., and Qiu, X. H. (2020). Capsaicinoid metabolism by the generalist Helicoverpa armigera and specialist $\mathrm{H}$. assulta: species and tissue differences. Pestic. Biochem. Physiol. 163, 164-174. doi: 10.1016/j.pestbp.2019. 11.013

Conflict of Interest: The authors declare that the research was conducted in the absence of any commercial or financial relationships that could be construed as a potential conflict of interest.

Copyright (c) 2021 Sun, Hou, Zhang, Dang, Yang, Zhao, Ma and Tang. This is an open-access article distributed under the terms of the Creative Commons Attribution License (CC BY). The use, distribution or reproduction in other forums is permitted, provided the original author(s) and the copyright owner(s) are credited and that the original publication in this journal is cited, in accordance with accepted academic practice. No use, distribution or reproduction is permitted which does not comply with these terms. 